\title{
Article
}

\section{D Printing to Increase the Flexibility of the Chemical Synthesis of Biologically Active Molecules: Design of On-Demand Gas Generation Reactors}

\author{
Kirill S. Erokhin ${ }^{1}$, Evgeniy G. Gordeev ${ }^{1}{ }^{\infty}$, Dmitriy E. Samoylenko ${ }^{2}{ }^{\circledR}$, Konstantin S. Rodygin ${ }^{1,2}$ \\ and Valentine P. Ananikov 1,2,*(D) \\ 1 N. D. Zelinsky Institute of Organic Chemistry Russian Academy of Sciences, Leninsky Prospect 47, \\ 119991 Moscow, Russia; erokhin@ioc.ac.ru (K.S.E.); gordeev_e@ioc.ac.ru (E.G.G.); k.rodygin@spbu.ru (K.S.R.) \\ 2 Institute of Chemistry, Saint Petersburg State University, Universitetsky Prospect 26, 198504 Peterhof, Russia; \\ d.samoylenko@spbu.ru \\ * Correspondence: val@ioc.ac.ru
}

Citation: Erokhin, K.S.; Gordeev, E.G.; Samoylenko, D.E.; Rodygin, K.S.; Ananikov, V.P. 3D Printing to Increase the Flexibility of the Chemical Synthesis of Biologically Active Molecules: Design of On-Demand Gas Generation Reactors Int. J. Mol. Sci. 2021, 22, 9919. https://doi.org/10.3390/ijms 22189919

Academic Editor: Vijay

Kumar Thakur

Received: 20 August 2021

Accepted: 10 September 2021

Published: 14 September 2021

Publisher's Note: MDPI stays neutra with regard to jurisdictional claims in published maps and institutional affiliations.

Copyright: (c) 2021 by the authors. Licensee MDPI, Basel, Switzerland. This article is an open access article distributed under the terms and conditions of the Creative Commons Attribution (CC BY) license (https:/ creativecommons.org/licenses/by/ $4.0 /)$
Abstract: The development of new drugs is accelerated by rapid access to functionalized and Dlabeled molecules with improved activity and pharmacokinetic profiles. Diverse synthetic procedures often involve the usage of gaseous reagents, which can be a difficult task due to the requirement of a dedicated laboratory setup. Here, we developed a special reactor for the on-demand production of gases actively utilized in organic synthesis $\left(\mathrm{C}_{2} \mathrm{H}_{2}, \mathrm{H}_{2}, \mathrm{C}_{2} \mathrm{D}_{2}, \mathrm{D}_{2}\right.$, and $\left.\mathrm{CO}_{2}\right)$ that completely eliminates the need for high-pressure equipment and allows for integrating gas generation into advanced laboratory practice. The reactor was developed by computer-aided design and manufactured using a conventional 3D printer with polypropylene and nylon filled with carbon fibers as materials. The implementation of the reactor was demonstrated in representative reactions with acetylene, such as atom-economic nucleophilic addition (conversions of 19-99\%) and nickel-catalyzed S-functionalization (yields 74-99\%). One of the most important advantages of the reactor is the ability to generate deuterated acetylene $\left(\mathrm{C}_{2} \mathrm{D}_{2}\right)$ and deuterium gas $\left(\mathrm{D}_{2}\right)$, which was used for highly significant, atom-economic and cost-efficient deuterium labeling of S,O-vinyl derivatives (yield 68-94\%). Successful examples of their use in organic synthesis are provided to synthesize building blocks of heteroatom-functionalized and D-labeled biologically active organic molecules.

Keywords: 3D printing; additive manufacturing; acetylene; carbon dioxide; hydrogen; organic synthesis

\section{Introduction}

The development of new drugs urgently requires accelerated chemical synthesis procedures to access key molecular building blocks and synthesize libraries of new molecules. Modular synthetic procedures based on simple starting materials are demanded the most to achieve cost-efficient and rapid preparation of new organic molecules. Heteroatomfunctionalized molecules are the key substances for modern pharma, and a new wave is stimulated by exploring deuterium-labeled (D-labeled) molecules, which show an improved pharmacokinetic profile. The use of acetylenic starting materials is one of the most efficient ways to achieve cost-efficient functionalization in eco-friendly organic synthesis with reduced generation of wastes.

Acetylene is one of the most important building blocks in organic synthesis due to its availability and the many transformations developed, such as vinylation [1], carbonylation [2,3], Favorsky reactions [4], and coupling reactions [5], among many others [6-8]. Advances in acetylene chemistry have recently been highlighted and have shown an emerging growing trend $[6,9]$. The transformations of acetylene have been implemented in industrial processes [10] and used in the development of a new generation of smart multifunctional materials [11,12]. 
However, the flammability and explosiveness of gaseous acetylene limits the scope of possible transformations compared to other alkynes. Special safety requirements should be followed, and dedicated specialized laboratory equipment (gas lines, gas cylinders, valves, etc.) is required for successful reactions with acetylene gas (Figure 1a). The use of such equipment involves a risk of leakage. Acetylene can often be stored in acetone solution in high-pressure gas cylinders; working with it also requires compliance with safety precautions.

Hydrogen and $\mathrm{CO}_{2}$ are essential reagents that are widely used for hydrogenation [13-15] and carboxylation [16-19] reactions, both in industry and laboratory practice. Each of the gases requires dedicated equipment to involve them in a diverse range of reactions.

The approach developed here is based on two key components: the use of on-demand production of gas from a suitable precursor and the design of the reactor using $3 \mathrm{D}$ printing. The precursor for acetylene is calcium carbide, powerful potential of which has recently been studied through a series of chemical transformations, where acetylene is formed by the addition of water [20-38]. However, the presence of calcium carbide, water, and calcium hydroxide (a side product) is not compatible with a large number of water- or base-sensitive chemical reactions. The same issue concerns the generation of other gases $\left(\mathrm{CO}_{2}\right.$ and $\left.\mathrm{H}_{2}\right)$. Therefore, the formation of gaseous reagents from precursors must be spatially separated to avoid interfering with the chemical process. We found that the design of the reactor for acetylene generation using $3 \mathrm{D}$ printing technology provides a complete solution to this complex problem.

Currently, additive manufacturing (AM), or 3D printing, is widely applied in many areas of science and technology, such as medicine [39-44], engineering [45-48], and material sciences [49-53]. In chemistry, 3D printing improves process efficiency by manufacturing fluidics [54-56], customized reactors for organic synthesis [57-61], and specific catalytic devices [62-64]. Key benefits of additive manufacturing include rapid prototyping and the creation of products with a complex architecture, the manufacture of which would be laborious or even impossible by classical methods [65]. AM involves several approaches potentially applicable in reactor design. Material extrusion (particularly, fused filament fabrication or FFF) stands out among them due to the low cost of personal 3D printers. Along with the wide possibilities of 3D printing for creating products of complex shapes, the FFF method is distinguished by the possibility of using it directly in the chemical laboratory, which is important since it significantly speeds up the optimization of product design. In addition, the FFF method allows for the use of a variety of materials, in particular polypropylene (PP) [66]. PP is available for 3D printing, while the production of complex PP parts by classical methods (turning and milling) requires significant costs and bulky equipment. For chemistry purposes, 3D printing allows for the design of reactors and devices to improve reaction efficiency [67-73].

Undoubtedly, customized gas generating equipment is demanded in organic synthesis. In this work, a reactor was developed for on-demand production of acetylene from calcium carbide. The reactor was manufactured by FFF additive manufacturing and comprehensively tested. Compared to gaseous acetylene from a gas cylinder, the use of the reactor is safer since acetylene was generated in the necessary amounts and immediately consumed in the reaction (Figure 1b). It is important to emphasize that storing and dosing $\mathrm{CaC}_{2}$ is fairly simple. The use of the reactor allows the synthesis to be carried out at atmospheric pressure and without the use of high-pressure equipment. In the absence of a gas pipeline, this makes it possible to avoid the use of bulky equipment and to reduce the dimensions of the setup to the size of the reaction vessel. The practical applicability of the designed acetylene reactor was thoroughly studied. It was successfully tested in reactions of nucleophilic addition of thiols and alcohols as well as the Ni-catalyzed addition of aryl disulfides to acetylene. The use of the reactor allowed the synthesis of target vinyl derivatives, 1,4-bis(arylthio)buta-1,3-dienes and 1,2-bis(arylthio)ethenes, with good conversions/yields. The reactor is universal and allows for generating not only acetylene, but also other gases for organic synthesis. This was shown with the examples of 
$\mathrm{H}_{2}, \mathrm{CO}_{2}, \mathrm{D}_{2}$, and $\mathrm{C}_{2} \mathrm{D}_{2}$, which were involved in hydrogenation, carboxylation, deuteration, and deuterated vinyl derivative synthesis, respectively. The compatibility of $3 \mathrm{D}$ printed parts with chemical reaction mixtures was explored, and reactor stability was investigated using scanning electron microscopy. The structural integrity of both the carbon fiber-filled nylon and polypropylene reactors was rather high even under harsh conditions, where the polypropylene reactor was more durable. Amazingly, a 3D printed reactor made from plastic was found to be highly stable and was reused up to 15 times despite the highly aggressive chemical medium. This work develops a methodology for AM application in organic synthesis with gaseous reagents.
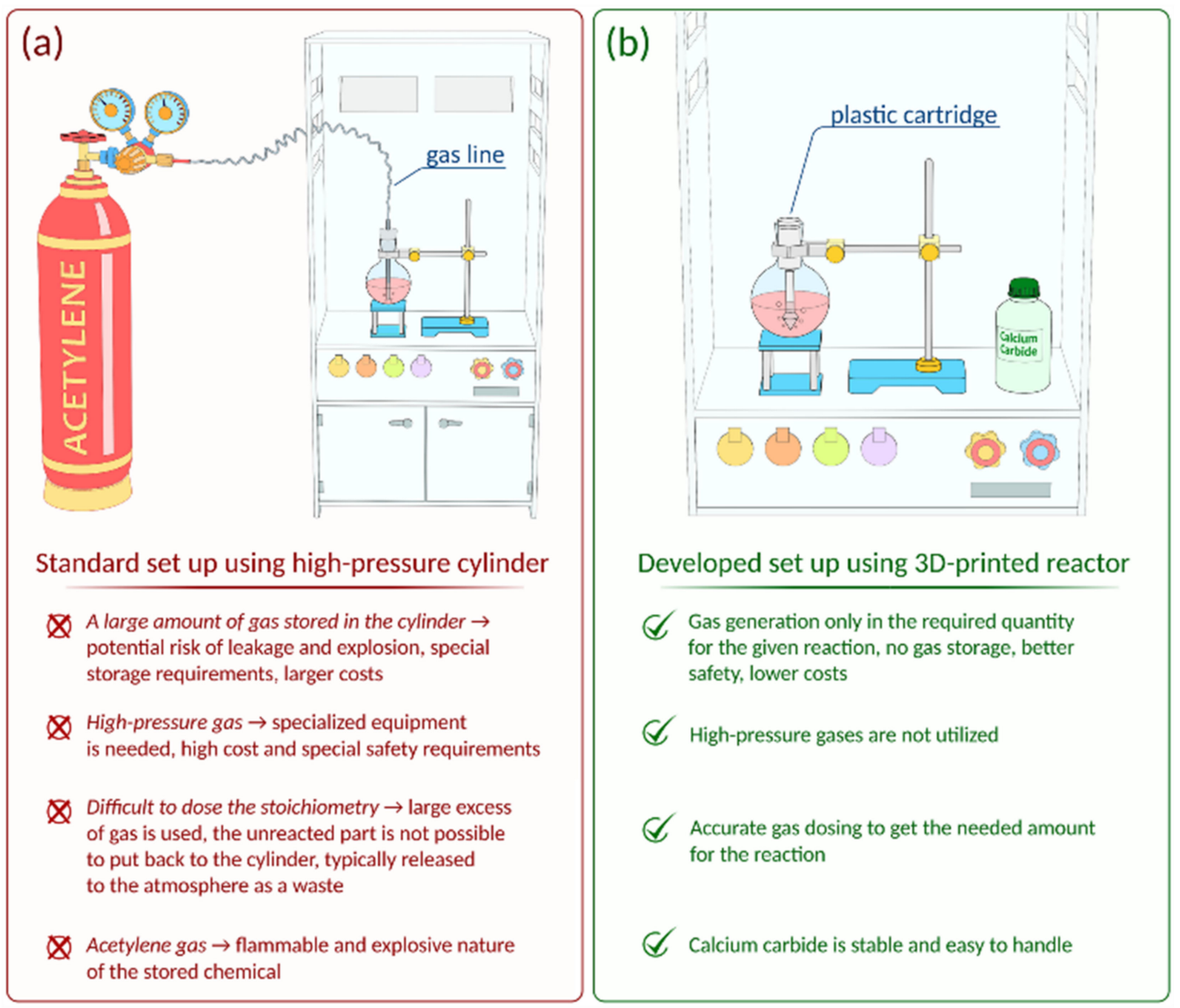

Figure 1. (a) Usage of a high-pressure acetylene cylinder (a standard approach); (b) application of a 3D printed on-demand acetylene generator (i.e., acetylene cartridge) without gas storage (cylinder-free approach, used in this work).

\section{Results}

\subsection{Design of the Reactor}

The idea is to create a reusable compact device for the on-demand generation of acetylene and its subsequent reaction that will solve the problems described above when using acetylene from a cylinder. For the reactor to be compact, it should fit into a reaction vessel. This reactor should have a minimum of joints, which reduces the risk of possible uncontrolled and significant leaks and the loss of generated acetylene. The possibility of varying its geometric parameters will expand the range of reaction vessels in combination with which the reactor can be used. When creating the reactor, 3D printing was used, since it allows you to quickly fabricate products with a complex structure.

The reactor was designed as a hollow cylinder with a bottom, in the center of which there is a hollow tube, which subsequently extends beyond the described "bar- 
rel" (Figure 2a and Figure S1). The cylinder used has a cut out, and the total reactor height is $97 \mathrm{~mm}$. The outer diameter of the cylinder is $25 \mathrm{~mm}$, and the wall thickness is $1.5 \mathrm{~mm}$. The inner diameter of the hollow tube is $3 \mathrm{~mm}$, and the wall thickness changed from 2.15 $\mathrm{mm}$ inside the hollow cylinder to $3 \mathrm{~mm}$ outside it. The hollow tube transforms into a conical extension with a diameter of $18 \mathrm{~mm}$ at the end. The extension has gas exhaust holes with a diameter of $1 \mathrm{~mm}$. The outer diameter of the cap is less than the inner diameter of the hollow cylinder of the reactor $(21.5 \mathrm{~mm})$. This is made for smooth entry of the cap into the reactor, which can be complicated in case of possible shrinkage of the material. The geometry and key dimensions of the reactor (shape, diameter, and total height) are consistent with the internal diameter and height of the reaction vessel (flask, tube, etc.). The total volume of reagents for the gas generation process defines the internal volume of the hollow cylinder and the external diameter of the central hollow tube. The length of the lower part is defined by the height of the solution in the reaction vessel and the necessary immersion depth of the reactor. The thickness of the outer wall is selected so that the wall is gas tight. The described reactor was designed for use in $50 \mathrm{~mL}$ polypropylene tubes. It should be noted that the geometrical parameters of the reactor and a number of the gas exhaust holes can be changed/customized if necessary. In the Supplementary Materials, we provide the computer-designed STL files, which can be used to tune the acetylene reactor for a particular vessel.
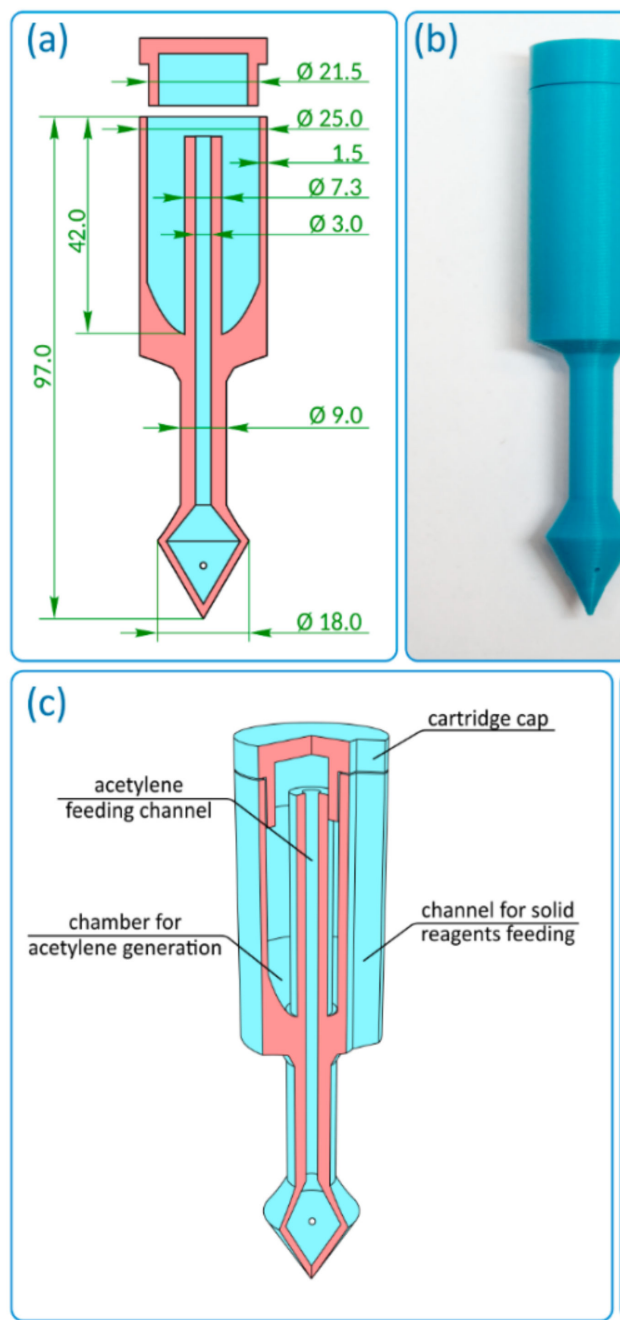
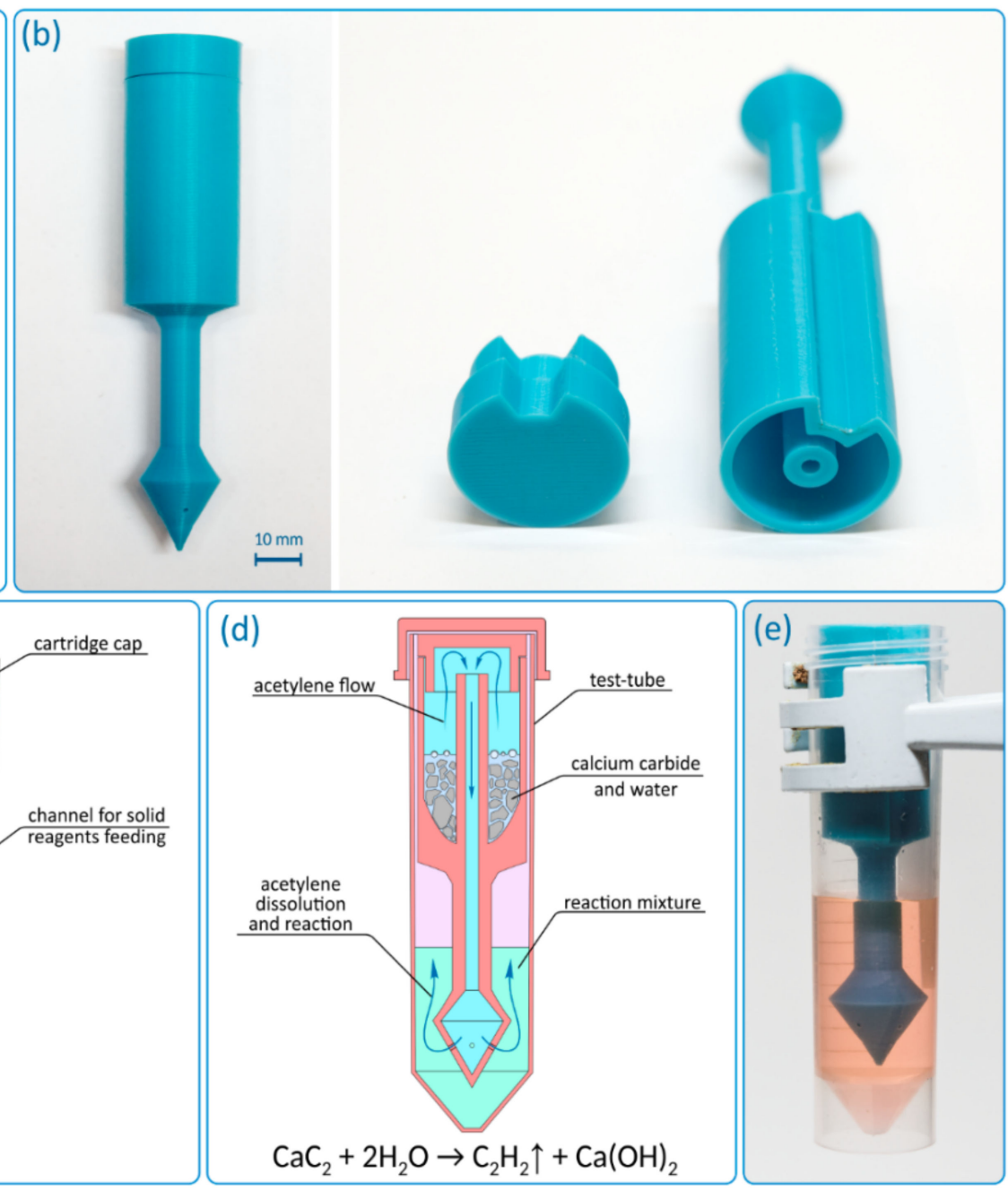

Figure 2. Design of reactor: (a) general design of the reactor, (b) photo of the 3D printed reactor with polylactide (PLA), (c) internal structure of the reactor, $(\mathbf{d})$ working principle of the reactor, and (e) photo of the ready-to-use 3D printed reactor inside a tube with reaction mixture. 
The first prototype was 3D printed with polylactide (PLA) and was monolithic (Figure $2 b$ ). The reactor contains the following functional components: an acetylene generation chamber, an acetylene feeding channel, and a cap (Figure 2c). The acetylene generation chamber is designed for the charging solid gas precursor (i.e., $\mathrm{CaC}_{2}$ ) and gas evolution reaction. The chamber is connected to the distributor (conical extension with gas exhaust holes) through the feeding channel. The acetylene generation chamber has a channel for solid reagent feeding (side cutout), which allows reagents to be loaded into the reaction vessel without removing the reactor.

First, the reagents for gas generation are loaded into the acetylene generation chamber $\left(\mathrm{CaC}_{2}+\right.$ water/solvent). Then the chamber is immediately closed with a cap. To seal the cap and tighten the joint, silicone grease may be used. After the start of the reaction, the evolved gas passes from the chamber through the feeding channel to a distributor (Figure 2d). The distributor divides the gas flow into several individual exhausts. The holes are located at a height of $\sim 5 \mathrm{~mm}$ to avoid contamination of the reaction solution in the vessel by the components from the acetylene generation chamber. When the components enter the feeding channel, they remain in the lower conical part of the reactor and do not interfere with the escape of gas through the holes. The manufactured acetylene reactor conveniently fits inside the tube and delivers acetylene directly into the reaction mixture (Figure 2e and Figure S2).

\subsection{Evaluation of Materials for 3D Printing of the Reactor}

In general, organic synthesis procedures are carried out in suitable solvents (e.g., acetone, chloroform, DMF, etc.). Parts made of plastics (e.g., 3D printed parts) may be incompatible with various solvents. To select a suitable material for reactor manufacturing, it is necessary to test the resistance of the plastics to the desired solvents.

A previous study showed that nylon, carbon fiber-filled nylon (CF-nylon), polypropylene (PP), polyethylene (PE), and polyoxymethylene (POM) are the most resistant materials to common organic solvents [74]. CF-nylon has the advantage of less shrinkage during AM than native nylon. To study a specific reaction system, we tested the resistance of three materials (PLA, CF-nylon, and PP) to acetonitrile and DMSO using an experimental procedure published earlier (Table 1) [74]. For this purpose, a 3D printed test model was placed in an empty bottle with an outer diameter of $30 \mathrm{~mm}$ and a height of $70 \mathrm{~mm}$. On top of the object was a steel bead that served as an indicator of mechanical integrity. The vial was carefully filled with $20 \mathrm{~mL}$ of solvent and tightly capped. Then, the behavior of the part was observed for $20 \mathrm{~h}$. The fall of the bead indicates the loss of mechanical integrity. PLA in acetonitrile undergoes swelling and subsequent delamination (detachment of the layer from one another), which leads to destruction of the part, and exposure to DMSO leads to slight swelling and transfer of the PLA dye into the solvent. CF-nylon and PP proved to be quite resistant to these solvents. There were no signs of a change in the structure of the part. For these reasons, the reactors were 3D printed with PP and CF-nylon for practical use. To obtain 3D printed reactors of high quality, the additional optimization of FFF parameters was carried out (Table S1 and Figure S3).

It should be noted that the products obtained by the FFF method are characterized by the anisotropy of mechanical properties: in the plane of the layers, the strength is higher than that between the layers. This should be taken into account when developing products for specific purposes. In some cases, a preliminary analysis of the mechanical properties of the resulting products is required [75-78]. However, in this work, reactors are developed for use in organic synthesis, in which low mechanical forces are applied. Gas generation occurs at atmospheric pressure and does not lead to an increase in pressure inside the reactor due to the immediate release of gas through the exhaust holes of the distributor. 
Table 1. Analysis of the stability of FFF parts made of various materials in organic and inorganic liquid media *

\begin{tabular}{cccc}
\hline Solvent & PLA & CF-nylon & PP \\
\hline Water & + & + & + \\
\hline Ethanol & + & + & + \\
\hline Acetone & - & + & + \\
\hline Acetonitrile & - & + & + \\
\hline DMF & - & + & + \\
\hline DMSO & \pm & + & + \\
\hline
\end{tabular}

* (+) material is stable during the experimental time, i.e., the shape of the part does not change; there is no dissolution of the outer layers of the material; $(-)$ the material is unstable during the experiment, there is a change in shape or destruction of the part; $( \pm)$ the material is moderately stable during the experimental time: swelling or slight dissolution of the outer layers is observed, the shape of the part does not change.

\subsection{Experimental Usage of the Reactor}

Calcium carbide was added to the acetylene generation chamber, and then a certain amount of water was added to the chamber to initiate the formation of acetylene, followed by closing the reactor with a cap. The exhaust acetylene flows through the feeding channel and escapes through the holes at the bottom. The lower part of the reactor should be placed in a solvent to saturate the reaction mixture with acetylene. The holes distribute the released acetylene into several streams, which increases the efficiency of solvent saturation. The intensity and time of gas evolution can be controlled by changing the concentration of water added to $\mathrm{CaC}_{2}$, which is achieved by dilution with another solvent inert to $\mathrm{CaC}_{2}$ (e.g., DMF or DMSO), as well as by gradual (or portion-wise) addition of water. An illustration of the use of the reactor is shown in Figure S2.

The use of computer-aided design of the reactor makes it easy to adapt the geometric parameters of the reactor to various reaction glassware (test tubes, flasks, etc.). Two different reactors with varying diameters and lengths are shown in Figure 3a.

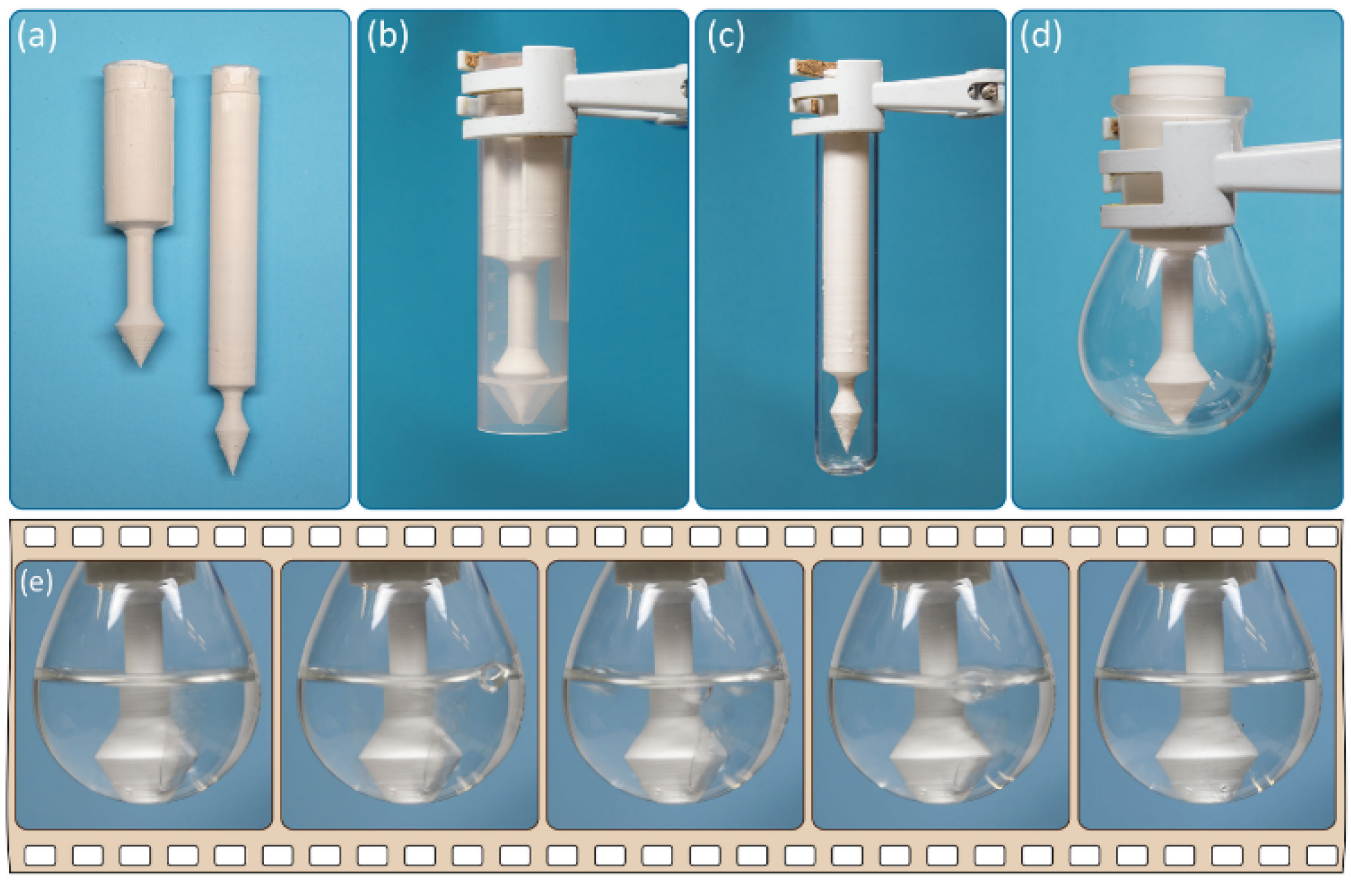

Figure 3. Reactors for acetylene generation 3D printed with PP: (a) different sizes of the reactors, (b) reaction setup for synthesis of 1,4-bis(arylthio)buta-1,3-dienes, (c) reaction setup for synthesis of 1,2-bis(arylthio)ethenes, (d) reaction setup for synthesis of vinyl derivatives, and (e) snapshots of acetylene release. 
Indeed, after customization of the geometry and 3D printing, the developed reactor was suitable for vessels of various shapes and sizes, e.g., test tubes and flasks (Figure 3b-d). After charging with calcium carbide and water, the generated acetylene gas was bubbled through the solution inside the reaction vessel (see Figure 3e).

\subsection{Evaluation of the Reactor Efficiency and Integration of Gas Drying and Flow Meter Capabilities}

A special validation was carried out to evaluate the efficiency of acetylene generation in the developed 3D printed reactor and for comparison with the standard procedure when acetylene is supplied from a cylinder (Figure 1a,b). For this, two independent saturation experiments were carried out. Acetylene was bubbled through DMSO at room temperature $\left(\sim 22{ }^{\circ} \mathrm{C}\right)$ for $20 \mathrm{~min}$ from two feeding sources: a standard gas cylinder and the reactor developed here (see Figure 1). Then, the concentration of acetylene in the solution was measured by ${ }^{1} \mathrm{H}$ NMR spectroscopy using an internal standard. In both cases, the concentration of acetylene in DMSO was the same within the experimental accuracy: $0.52 \pm 0.03 \mathrm{mmol} / \mathrm{mL}$ for the developed reactor and $0.47 \pm 0.12 \mathrm{mmol} / \mathrm{mL}$ for a standard cylinder (Figure S4). The local generation of acetylene in the developed reactor resulted in a better reproducibility of the concentration of dissolved acetylene.

Varying the shape of the gas distribution tip. A conical gas distribution tip may not fit in some cases. Additive manufacturing allows for varying the shape of this part of the reactor to better fit the bottom of the reaction vessel. We tested the distribution of gaseous acetylene depending on the shape of the lower part of the reactor. We 3D printed several types of reactors (Figure 4) with different distributors and tested them in saturation experiments. Plastic reactors were 3D printed with spherical and cylindrical distributors and without a tip (Figure $4 \mathrm{~b}-\mathrm{d}$ and Figure S5). Saturation experiments showed the same acetylene concentrations in all cases (Table 2). Therefore, the shape of the distributor is flexible and can vary depending on the specific reaction or equipment.

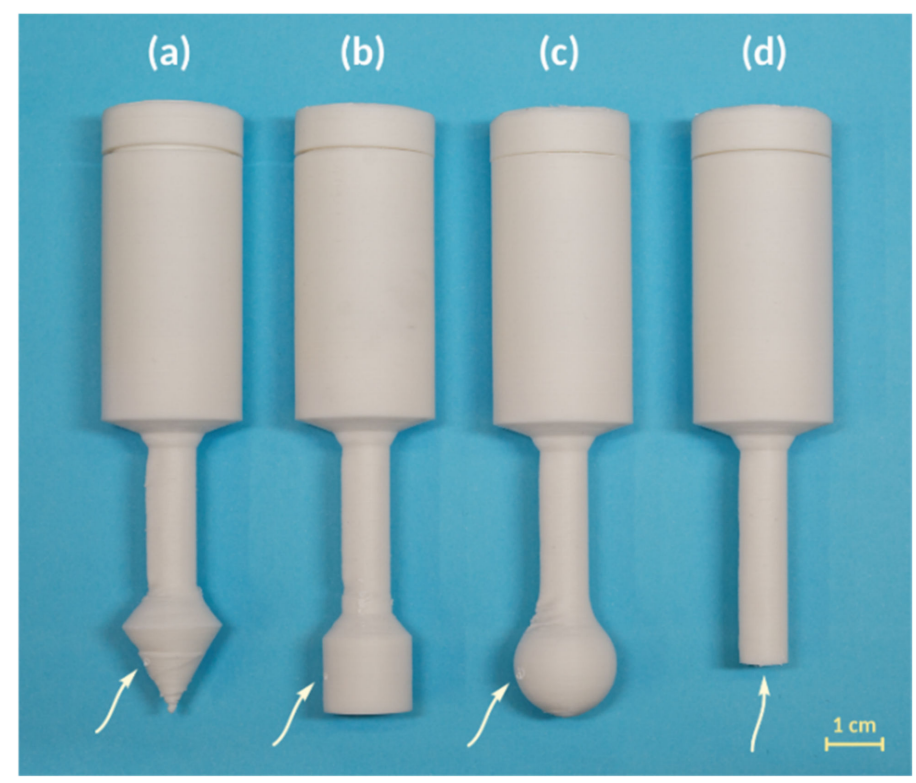

Figure 4. 3D printed plastic reactors with distributors of different shapes (arrow points on gas exhaust holes): (a)—conical; (b)—cylindrical; (c)—spherical; (d)—without a tip.

Table 2. Concentrations of acetylene in DMSO depending on feeding shape.

\begin{tabular}{cccccc}
\hline Reactor & Figure $4 \mathbf{a}$ & Figure $4 \mathbf{b}$ & Figure $4 \mathbf{c}$ & Figure $4 \mathbf{d}$ & $\begin{array}{c}\text { Acetylene from } \\
\text { Gas Cylinder }\end{array}$ \\
\hline $\begin{array}{r}\mathrm{C}\left(\mathrm{C}_{2} \mathrm{H}_{2}\right), \\
\mathrm{mmol} / \mathrm{mL}\end{array}$ & $0.54 \pm 0.01$ & $0.56 \pm 0.02$ & $0.56 \pm 0.04$ & $0.55 \pm 0.05$ & $0.47 \pm 0.12$ \\
\hline
\end{tabular}


Reactor with drying compartment. Acetylene generated in a designed reactor may be wet due to the use of water to produce gas. Some reactions are tolerant to the presence of trace water, and acetylene can be used directly. However, the presence of water may be fatal for a variety of reactions (especially those catalyzed by metals). To integrate the drying compartment, we increased the internal diameter of the feeding channel inside the acetylene generation chamber from 3 to $5.3 \mathrm{~mm}$ due to the decrease of its wall thickness. Extra space inside the feeding channel was filled with the drying agent (granular anhydrous calcium chloride). The reactor was tested in saturation/drying experiments, which were similar to the saturation experiment described above. Acetylene was bubbled through DMSO at room temperature $\left(22{ }^{\circ} \mathrm{C}\right)$ for $20 \mathrm{~min}$ with the use of the reactor. Then, the concentration of water in the solvent was measured by Karl Fischer titration. The experiment showed the efficiency of the drying compartment (Table 3). It should be noted that the increase in water concentration during bubbling is partially caused by the adsorption of moisture from air. When necessary, the diameter or height of the drying compartment can be enlarged.

Table 3. Content of water in DMSO before and after saturation with acetylene.

\begin{tabular}{ccccc}
\hline Drying Agent & $\begin{array}{c}\text { DMSO before } \\
\text { Saturation }\end{array}$ & $\begin{array}{c}\text { No Drying } \\
\text { Agents }\end{array}$ & $\mathbf{C a C l}_{\mathbf{2}}$ & $\begin{array}{c}\text { Acetylene from Gas } \\
\text { Cylinder }\end{array}$ \\
\hline $\mathrm{C}\left(\mathrm{H}_{2} \mathrm{O}\right), \mathrm{wt} \%$ & $0.235 \pm 0.008$ & $0.442 \pm 0.009$ & $0.354 \pm 0.003$ & $0.335 \pm 0.012$ \\
\hline
\end{tabular}

Reactor with an integrated float-type flow meter. Additive technologies make it possible to carry out significant modifications of the reactor to optimize its design in various tasks. In particular, this work demonstrated the possibility of full integration into the reactor of a float-type flow meter while retaining the possibility of using the reactor precisely as a cartridge for generating gases inside a flask or test tube (Figure 5). In a reactor with a flow meter, gas, after being generated in the chamber, enters a central channel (Figure $5 \mathrm{a}, \mathrm{b})$, which is connected to the flow meter channel. After passing through the flow meter channel, the gas enters the feeding channel and goes further into the reaction mass. Thus, to ensure the functionality of the flow meter, the gas flow changes its direction of motion several times. The flow meter channel is cylindrical, and a spherical plastic float is used as a flow indicator. To make the position of the float visible, the reactor was made of transparent plastic. It should be noted that FFF technology does not allow for obtaining completely transparent parts, even in the case of using completely transparent plastics, since the walls of the part contain many defects that scatter light. However, when using thin walls and with some optimization of FFF parameters, the transparency of the reactor is sufficient to visually identify the position of the float (Figure $5 c, d$ ). The float can be either a ready-made plastic ball of suitable size and weight or a ball made by additive manufacturing. In this case, the ball was 3D printed from two halves, which were then joined together; that is, the float was hollow to ensure optimal mass. This makes it possible to finely adjust the mass of the float by adding small pieces of plastic or glue drops to the inner cavity. The integrated flow meter can be used not only for a qualitative indication of the gas flow rate, but also for quantitative measurements since it allows for calibration with an external compressor with a precisely set gas flow rate (Figure S6). 


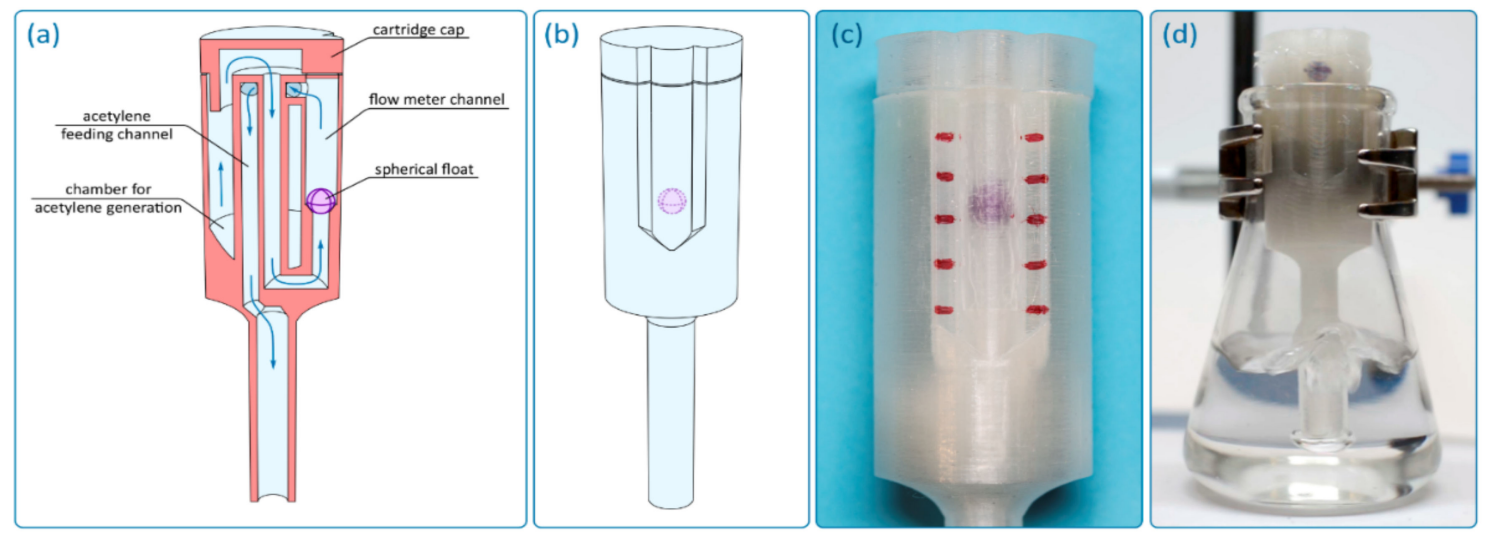

Figure 5. Reactor with an integrated float-type flow meter: (a) sectional view of the reactor, illustrating the system of channels through which the gas flow moves (shown by blue arrows); (b) general schematic view of the reactor; (c) detailed view of the reactor with the float in middle position; (d) during the acetylene release, the float moves to the upper part of the flow meter channel.

\subsection{Application of the Reactor in Organic Synthesis}

Three synthetic procedures of practical importance were chosen to test the performance of the 3D printed reactor. We used the following procedures: synthesis of vinyl derivatives by nucleophilic addition of alcohols, thiols, and amines [79]; synthesis of 1,4-bis(arylthio)buta-1,3-dienes by nickel-catalyzed addition of aromatic disulfides to acetylene under homogeneous conditions [80]; and synthesis of 1,2-bis(arylthio)ethenes by nickel-catalyzed reaction under heterogeneous conditions [80].

It should be noted that the mode of adding a liquid reagent to a solid in a gas generation chamber is determined by the dispersity of the solid reagent and the concentration of the liquid reagent. In the case of powder, liquid should be added dropwise to avoid excessive gas evolution, which could lead to the contamination of the reaction solution with reagents from the gas generation chamber. In the case of a granular reagent, adding the liquid reagent in one portion may be sufficient for sustained gas evolution. As a general rule, the smaller the particle size of the solid reagent is, the more accurately the liquid must be fed. The intensity of the gas evolution process can be reduced by diluting the liquid reagent.

Synthesis of vinyl derivatives. CF-nylon and PP reactors were tested in the vinylation reaction (Figure 6). An additional hole was drilled in the cap and sealed with rubber to slowly supply water from a syringe to the carbide chamber. Carbide and DMSO were loaded into the acetylene generation chamber of the reactor, benzyl alcohol was used as a model substrate, and $\mathrm{KOH}$ and $\mathrm{KF}$ were loaded into the flask. Then, the calculated amount of water was injected into the carbide chamber through the septum. After optimization of the reaction conditions (Tables S2 and S3), the scope of other substrates was tested (Table 4).

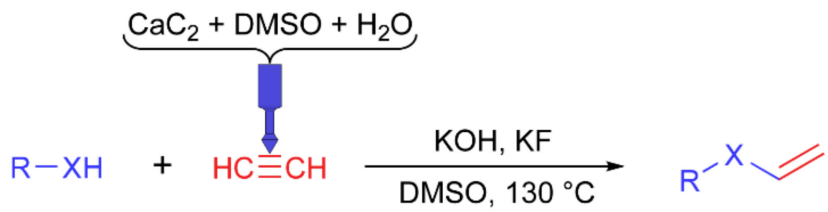

$\mathrm{X}=\mathrm{O}, \mathrm{S}, \mathrm{N}$

$\mathrm{R}=\mathrm{Alk}, \mathrm{Ar}$

Figure 6. Vinylation reaction. 
Table 4. Reaction conditions and product yields of the synthesized vinyl derivatives ${ }^{a}$.

\begin{tabular}{|c|c|c|c|c|c|c|}
\hline № & Substrate & Reactor & $\begin{array}{l}\text { Weight of } \\
\mathrm{CaC}_{2}, \mathrm{~g}\end{array}$ & $\begin{array}{l}\mathrm{T}, \\
{ }^{\circ} \mathrm{C}\end{array}$ & $\begin{array}{c}\text { Reaction Time, } \\
\text { h }\end{array}$ & $\begin{array}{c}\text { Conversion, } \\
\text { Mass \% }\end{array}$ \\
\hline \multirow{3}{*}{1} & \multirow{3}{*}{ Benzyl alcohol } & CF-nylon & 1.47 & 130 & 1 & 99.2 \\
\hline & & PP & 1.47 & 120 & 3 & 92.2 \\
\hline & & PP & 1.47 & 140 & 1 & 99.9 \\
\hline 2 & Octanol-1 & CF-nylon & 1.47 & 130 & 1 & 54.1 \\
\hline \multirow{3}{*}{3} & \multirow{3}{*}{ Undecanol-1 } & PP & 1.47 & 130 & 1 & 57.6 \\
\hline & & CF-nylon & 2.00 & 130 & 1 & 57.0 \\
\hline & & PP & 2.00 & 130 & 1 & 49.5 \\
\hline \multirow{3}{*}{4} & \multirow{3}{*}{ Citronellol } & PP & 1.47 & 130 & 1 & 67.4 \\
\hline & & PP & 2.00 & 130 & 1 & 69.6 \\
\hline & & CF-nylon & 2.00 & 130 & 1 & 62.2 \\
\hline 5 & Menthol & CF-nylon & 1.47 & 130 & 1 & 21.8 \\
\hline 6 & Fenchol & PP & 1.47 & 130 & 1 & 40.7 \\
\hline \multirow{4}{*}{7} & \multirow{4}{*}{1,10 -Decanediol ${ }^{b}$} & CF-nylon & 1.47 & 130 & 1 & 68.1 \\
\hline & & PP & 1.47 & 130 & 1 & 66.7 \\
\hline & & CF-nylon & 2.00 & 130 & 1 & 78.8 \\
\hline & & $\mathrm{PP}$ & 2.00 & 130 & 1 & 74.5 \\
\hline \multirow{2}{*}{8} & \multirow{2}{*}{ 1-Dodecanethiol } & CF-nylon & 1.47 & 130 & 1 & 99.9 \\
\hline & & $\mathrm{PP}$ & 1.47 & 130 & 1 & 99.9 \\
\hline \multirow{3}{*}{9} & \multirow{3}{*}{ Thiophenol } & CF-nylon & 1.47 & 130 & 1 & 56.0 \\
\hline & & CF-nylon & 2.00 & 130 & 1 & 45.2 \\
\hline & & $\mathrm{PP}$ & 2.00 & 130 & 1 & 46.7 \\
\hline 10 & p-Tolyl thiophenol & CF-nylon & 1.47 & 130 & 1 & 52.1 \\
\hline \multirow{2}{*}{11} & \multirow{2}{*}{ Diphenyl amine } & CF-nylon & 2.00 & 130 & 2 & 70.4 \\
\hline & & $\mathrm{PP}$ & 2.00 & 130 & 2 & 76.0 \\
\hline \multirow{3}{*}{12} & \multirow{3}{*}{ Indole } & CF-nylon & 2.00 & 130 & 1 & 48.1 \\
\hline & & CF-nylon & 1.47 & 140 & 1 & 41.1 \\
\hline & & PP & 1.47 & 140 & 1 & 36.0 \\
\hline 13 & Carbazole & CF-nylon & 1.47 & 130 & 1 & 19.3 \\
\hline
\end{tabular}

${ }^{a}$ Reaction conditions: substrate $(7.7 \mathrm{mmol})$, potassium fluoride $(9.2 \mathrm{mmol})$, potassium hydroxide $(9.2 \mathrm{mmol})$, calcium carbide $(23 \mathrm{mmol})$, and DMSO $(2 \mathrm{~mL}){ }^{b} 3.85 \mathrm{mmol}$ of the substrate was used instead.

The conversion was higher with the CF-nylon reactor than with the PP reactor. Surprisingly, despite the harsh reaction conditions, both 3D printed reactors were stable. Neither the superbasic medium nor the high temperature resulted in visible destruction or melting of the reactors. Compared with each other, the PP reactor was more stable than the $\mathrm{CF}-$ nylon reactor. The decrease in the yield of some products is associated with the high volatility of the final products.

Synthesis of 1,4-bis(arylthio)buta-1,3-dienes. In the reaction of aromatic disulfide addition to acetylene, the competitive formation of 1,2-bis(arylthio)ethene and 1,4-bis(arylthio)buta1,3-diene is typically observed. High selectivity for the formation of one of the two products was achieved using a set of optimal reaction conditions, namely, a phosphine ligand and a solvent. Before the reaction, acetylene was bubbled through the solvent in a water ice bath for $30 \mathrm{~min}$ to saturate it. The diene synthesis was carried out under additional acetylene pressure, which was provided by connecting a gas cylinder to a test tube with reagents. 
When pure water is added to calcium carbide, the reaction is extremely intense. As a result, the gas evolution time was insufficient to saturate the solvent (less than $10 \mathrm{~min}$ ). For a less intense reaction, water $(3 \mathrm{~mL})$ was added to a suspension of $\mathrm{CaC}_{2}(3 \mathrm{~g})$ in $\mathrm{DMF}$ $(4 \mathrm{~mL})$, which made it possible to increase the gas evolution time to $\sim 30 \mathrm{~min}$.

The reaction of 1,4-bis(arylthio)buta-1,3-diene synthesis was carried out under homogeneous conditions and was insensitive to moisture. It was found that the absence of stirring did not lead to a decrease in the product yield. Here, we used a 3D printed reactor with PP. Before the start of the reaction, the solvent in the polypropylene tube was saturated with acetylene using the designed reactor. Then the rest of the reagents were added. During the reaction, the reactor remained in the tube, which provided additional gas pressure.

Similar yields of 1,4-bis(phenylthio)buta-1,3-diene were obtained using the reactor developed here (Figure 7) and in the test experiment with acetylene supplied from a gas cylinder. Thus, the 3D printed reactor developed here is highly efficient and flexible for different reactions.

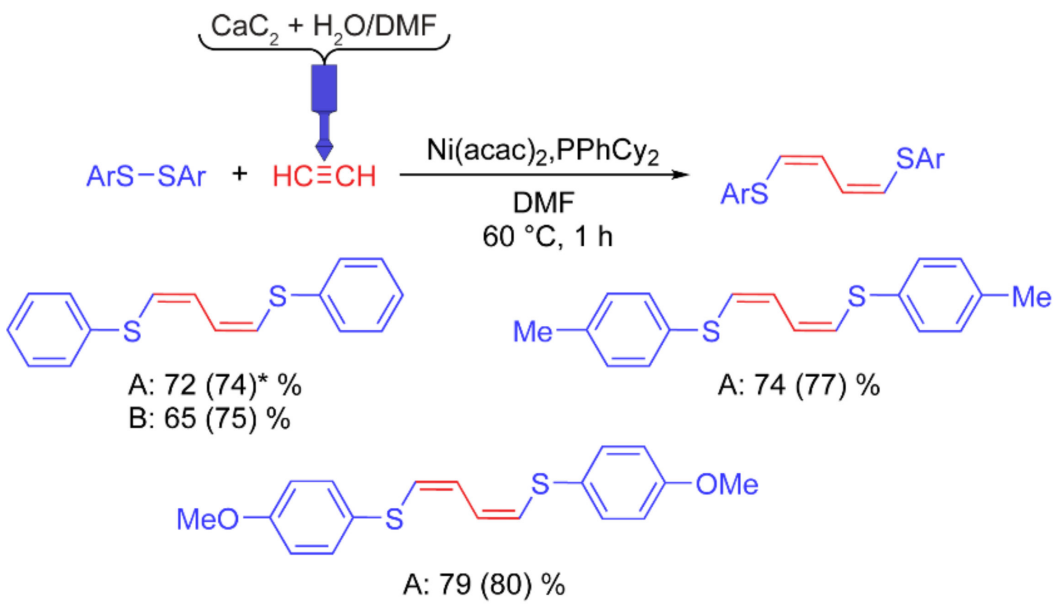

Figure 7. Scope of 1,4-bis(arylthio)buta-1,3-diene synthesis using the designed reactor (A) and acetylene from a gas cylinder (B). ${ }^{*}$ NMR yields in parentheses.

Synthesis of 1,2-bis(arylthio)ethenes. The selective formation of 1,2-bis(arylthio)ethene can be achieved with the use of heterogeneous catalysis and therefore requires stirring. Moisture is detrimental to this reaction and results in lower yields. A pre-saturated solvent is sufficient to introduce acetylene into the reaction solution. Additional acetylene pressure is not required, so the presence of the reactor in the reaction vessel during the reaction is not necessary.

Early experiments showed that the polypropylene tube was unable to withstand the pressure of acetylene, resulting in gas loss and, consequently, product traces. In the ${ }^{1} \mathrm{H}$ NMR spectrum of the reaction solution, signals of water and DMF were found, which indicates that the reagents from the acetylene generation chamber ingress into the saturated solvent. This is caused by the intense release of acetylene in the first minutes after adding a $\mathrm{DMF} /$ water mixture $(4 \mathrm{~mL} / 3 \mathrm{~mL})$ to $\mathrm{CaC}_{2}$.

To prevent the ingress of water and DMF into the reaction solvent, the dimensions of the reactor were changed, and the height of the acetylene generation chamber was increased (Figure 3a,c). A PP reactor was used for this reaction. To avoid too intense of a reaction of $\mathrm{CaC}_{2}$ with water, the $\mathrm{DMF} /$ water mixture was added in two portions at $15 \mathrm{~min}$ intervals. Using this approach, together with the reaction in screw-capped tubes, yields of the target product were achieved similar to those obtained using acetylene from a gas cylinder (Figure 8). 


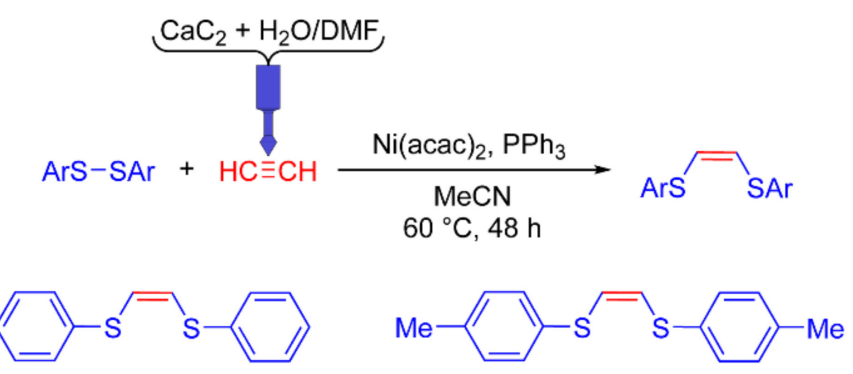
A: $77(82)^{*} \%$
A: 95 (99) \%

B: $74(82) \%$

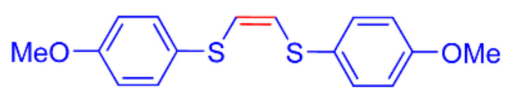

A: $90(99) \%$

Figure 8. Scope of the reaction of 1,2-bis(arylthio)ethene synthesis using the designed reactor (A) and acetylene from a gas cylinder (B). ${ }^{*}$ NMR yields in parentheses.

An important advantage of using the developed reactors in comparison with gaseous acetylene is the consumed time for the experiment. The main issues of using gaseous acetylene are the availability of a cylinder with acetylene and access to the place of its storage. In a number of locations, the storage of acetylene cylinders may be restricted due to their potential explosion hazard. The use of an acetylene generation reactor saves time in preparing the experiment.

\subsection{Generation of $\mathrm{CO}_{2}, \mathrm{H}_{2}$, and $\mathrm{C}_{2} \mathrm{D}_{2}$}

Construction of the designed reactor allows it to be used to produce other gases $\left(\mathrm{CO}_{2}\right.$, $\mathrm{H}_{2}$, etc.). To demonstrate this, we performed several essential organic reactions involving gases such as carboxylation of the Grignard reagent, hydrogenation of an alkene, and synthesis of deuterated products using the developed 3D printed reactor. Hydrogen and carbon dioxide are available in gas cylinders (Figure 1). However, these gases require dedicated gas transfer lines with special requirements fulfilled in each case. Our reactor is universal customized equipment, which simplifies regular laboratory experiments.

Carboxylation reaction $\left(\mathrm{CO}_{2}\right.$ generation). The suitability of the reactor for the generation of $\mathrm{CO}_{2}$ was demonstrated in the carboxylation of n-butyl magnesium bromide. To generate $\mathrm{CO}_{2}$, sodium bicarbonate powder was loaded into a gas generation chamber. Then, an aqueous solution of sulfuric acid was added. To provide a slow and smooth generation of $\mathrm{CO}_{2}$, acid was added dropwise using a syringe pump for $1 \mathrm{~h}$. This allowed for the valeric acid to be achieved in a high yield (Figure $9 a$ ).

Hydrogenation reaction ( $\mathrm{H}_{2}$ generation). Hydrogen was generated by adding an aqueous solution of sulfuric acid to granular $\mathrm{Zn}$ loaded into the gas generation chamber. The required volume of the acid was added in one portion, which provided a smooth generation of $\mathrm{H}_{2}$ for $\sim 1.5 \mathrm{~h}$. Hydrogenation of ethyl cinnamate was chosen as a model reaction (Figure 9b). Ethyl 3-phenyl propionate was the only product of the reaction. After $1.5 \mathrm{~h}$ of the reaction, the conversion of the substrate was $68 \%$. Then, the reaction mixture was removed from the gas generation chamber, and new portions of $\mathrm{Zn}$ and sulfuric acid were added. The reaction continued for another $90 \mathrm{~min}$. This made it possible to achieve complete conversion of the substrate. 


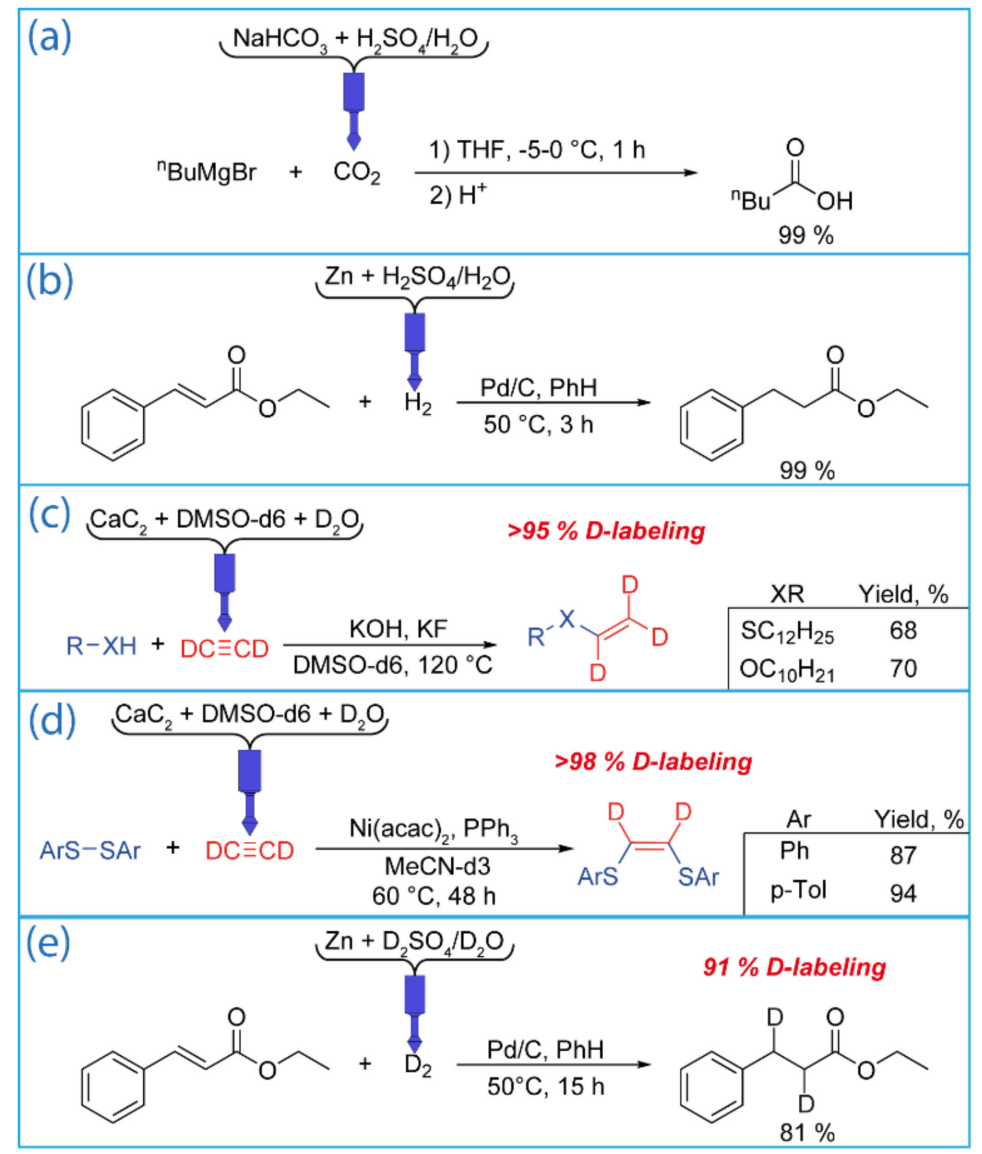

Figure 9. Reactions with gases generated with the use of the designed reactor: (a) carboxylation of n-butyl magnesium bromide, (b) hydrogenation of ethyl cinnamate, (c) nucleophilic addition to $\mathrm{C}_{2} \mathrm{D}_{2}$, (d) Ni-catalyzed addition to $\mathrm{C}_{2} \mathrm{D}_{2}$, and (e) deuteration of ethyl cinnamate.

Synthesis of deuterated acetylene and labeled $O, S$-vinyl derivatives $\left(C_{2} D_{2}\right.$ generation). The usage of gaseous reagents in laboratory practice is relatively rare due to special reaction conditions, equipment, and safety requirements. Commercially available gases in balloons can be used in some simple procedures. However, labeled gases can be packaged on demand only, shipping is extremely difficult, and special safety requirements must be fulfilled. Because of this, the price of these gases is quite high. Moreover, labeled gases are supplied under atmospheric pressure (custom synthesis), and a vacuum line is needed to retrieve the gas. These difficulties significantly complicate the reactions involving $C_{2} D_{2}$.

The use of the 3D printed reactor easily expands synthetic opportunities in the synthesis of valuable labeled gases. When the water required for the hydrolysis of calcium carbide is replaced with heavy water (deuterium oxide), deuteroacetylene $C_{2} D_{2}$ is released from $\mathrm{CaC}_{2}$. Compared to the literature, one can easily highlight the advantages of atomeconomic D-labeling through the use of $\mathrm{C}_{2} \mathrm{D}_{2}$. Alternative synthetic approaches to incorporate deuterium labels are based on base- or metal-catalyzed exchange reactions [81-86], $\mathrm{D}_{2}$-gas use [87], or previously labeled compounds [88-90]. Exchange reactions consume a significant amount of deuterated starting substrate when the desired product is mixed with a many-fold excess of a deuterated source several times [91,92]. Another approach to the synthesis of deuterated compounds is the use of commercially available hydrogen gas $\mathrm{D}_{2}$, which may be rather expensive. The use of this approach is associated with the storage difficulties, explosive nature, limited scope of reactions, and volatility of gaseous $\mathrm{D}_{2}$. Thus, the scope of appropriate labeling methods is highly limited, and the synthesis of $\mathrm{C}_{2} \mathrm{D}_{2}$ gas without cylinders and gas equipment is an excellent opportunity.

To test a 3D printed reactor in $\mathrm{C}_{2} \mathrm{D}_{2}$ synthesis, a nucleophilic addition reaction of a thiol and alcohol to deuterated acetylene was carried out (Figure 9c). The same conditions 
were used except with $\mathrm{D}_{2} \mathrm{O}$ instead of $\mathrm{H}_{2} \mathrm{O}$. As a result, deuterated vinyl sulfide $\mathrm{C}_{12} \mathrm{H}_{25^{-}}$ $\mathrm{S}-\mathrm{CD}=\mathrm{CD}_{2}$ and deuterated vinyl ether $\mathrm{C}_{10} \mathrm{H}_{21}-\mathrm{O}-\mathrm{CD}=\mathrm{CD}_{2}$ were successfully synthesized and isolated in $68 \%-70 \%$ yields and deuterium enrichment was greater than $95 \%$. A similar protocol of $\mathrm{C}_{2} \mathrm{D}_{2}$ generation was used to conduct the reaction of Ni-catalyzed addition of $\mathrm{Ar}_{2} \mathrm{~S}_{2}$ to deuterated acetylene (Figure 9d). This allowed for the synthesis and isolation of deuterated 1,2-bis(arylthio)ethenes with high yields (87-94\%) and high deuterium enrichment (more than 98\%). In both reactions, the obtained deuterated compounds were stable and treated as usual without any exchange side processes. Note that using a reactor reduces the total volume of expensive deuterated acetylene compared with the common bubbling method.

Deuteration reaction ( $D_{2}$ generation). The generation of $D_{2}$ and the subsequent deuteration reaction of ethyl cinnamate were carried out in the same manner as for $\mathrm{H}_{2}$ (Figure 9e). It should be noted that the deuteration reaction proceeded more slowly than the hydrogenation reaction. This is probably due to the kinetic isotope effect. After $3 \mathrm{~h}$ of reaction, the conversion was only $50 \%$. Therefore, the reaction was continued for another $12 \mathrm{~h}$. This made it possible to achieve a conversion of $81 \%$ with $90 \%$ deuterium enrichment. Deuterated ethyl 3-phenyl propionate was the only product of the reaction.

\subsection{Reusability of the 3D Printed Reactor}

Since the reactor was stable under the reaction conditions, we studied the possibility of reusing the reactors. The reactor was stable during operation even under the harsh conditions of the nucleophilic addition reaction. The reactor, 3D printed with CF-nylon, was able to run nine times without losing structural integrity in the nucleophilic addition of benzyl alcohol to acetylene. However, after the 10th cycle, the neck of the reactor broke off (Figure S7). The loss of the mechanical strength of the reactor is associated with the action of the solvent and reagents at high temperatures on the surface layers, which has been repeatedly shown earlier [74].

In our case, the PP reactor was more stable than the CF-nylon reactor. It withstood 15 reaction cycles at $80-140^{\circ} \mathrm{C}$. No signs of destruction were observed after the 15 th cycle (Figure 10 and Figure S8).

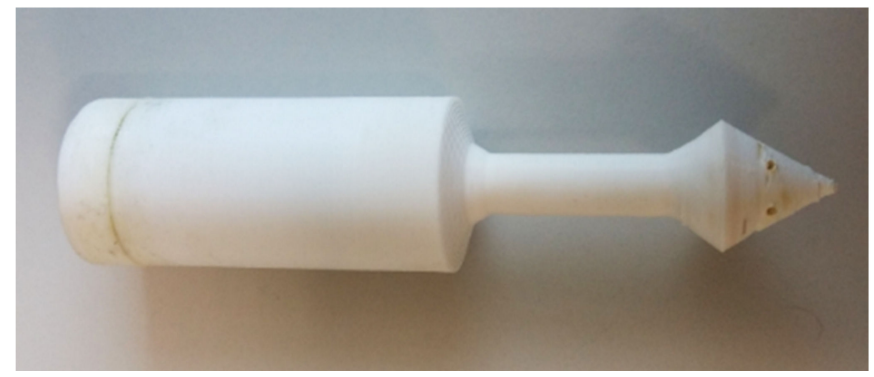

Figure 10. Photo of the PP reactor after the 15th reactor cycle (the reactor was used in 15 successive experiments).

Thus, the use of reactors in other synthetic technologies seems to be very promising. $\mathrm{CF}$-nylon is suitable for higher temperature processes due to the higher heat deflection temperature $(\mathrm{HDT})$ of $160^{\circ} \mathrm{C}$ at $0.46 \mathrm{MPa}\left(\mathrm{T}_{\mathrm{m}}=220^{\circ} \mathrm{C}\right)$ in comparison with $\mathrm{PP}\left(\mathrm{HDT}=100^{\circ} \mathrm{C}\right.$, $\left.\mathrm{T}_{\mathrm{m}}=160^{\circ} \mathrm{C}\right)[93]$.

As is currently well known, FFF parts have a porous structure and a rough surface. This can be the reason for the adsorption of the components of the reaction mixture, which is especially important in the case of catalytic processes. In some cases, even a small decrease in catalyst concentration can lead to a significant decrease in the reaction yield. Consequently, their use in catalytic reactions can be limited, in contrast to noncatalytic reactions. 


\subsection{Analysis of the Reactor Surface}

Harsh reaction conditions (heating up to $140{ }^{\circ} \mathrm{C}$ ), organic solvents, and inorganic alkalis could completely destroy a 3D printed reactor or significantly change its structure. In addition, transparent pores and delamination may appear. To assess the consequences of the reactions with use of the reactor and the possibility of reuse, we analyzed the surface of the reactors for destruction after several cycles of reactions. The surfaces of both PP and CF-nylon reactors before and after the reactions were examined using field emission scanning electron microscopy (FE-SEM) and energy dispersive X-ray spectroscopy (EDX). The surface of the PP reactor was initially rough, with rare fine pores observed between the clearly defined layers (Figure 11a). After the reaction of 1,4-bis(phenylthio)buta-1,3-diene, no changes in the surface morphology were found (Figure 11b). EDX showed the absence of $\mathrm{Ni}, \mathrm{S}$, and $\mathrm{P}$ on the surface (Figure S10), i.e., no adsorption of reagents on PP occurred. In the case of the synthesis of benzyl vinyl ether, no signs of surface destruction were found after five reaction cycles, which is very promising, given the harsh reaction conditions (superbasic medium and high temperature) (Figure 11c). However, deposits of organic matter as well as KF and $\mathrm{KOH}$ were observed, and were confirmed by EDX (Figures S10 and S12).

a)

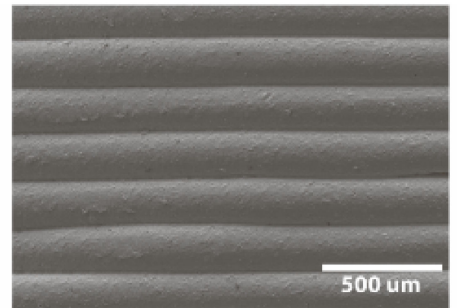

b)

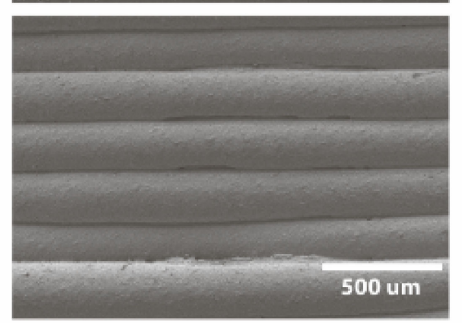

c)

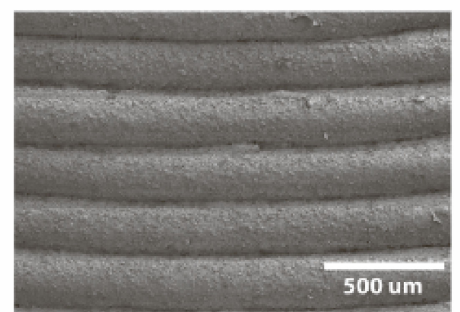

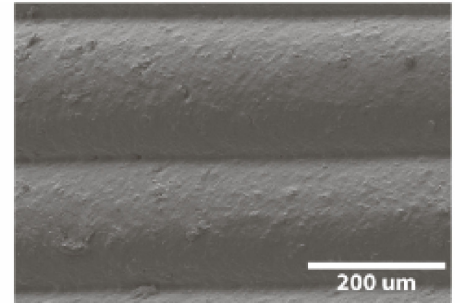
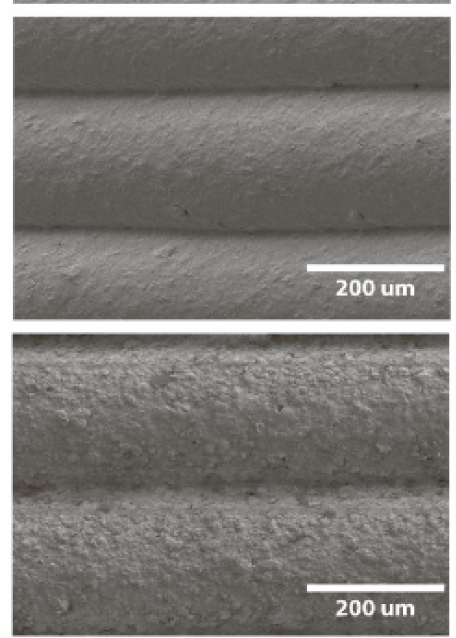
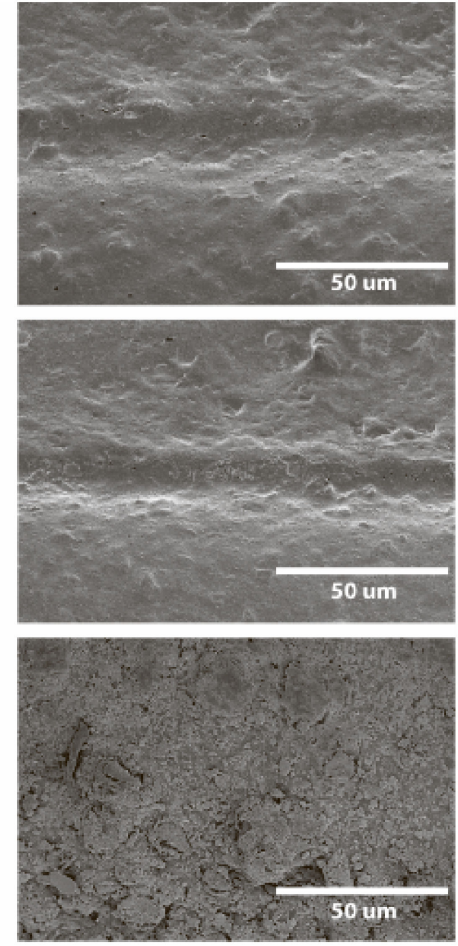

Figure 11. SEM images of the 3D printed reactor surface with PP at different magnifications: (a) before the reaction, (b) after one cycle of reaction of 1,4-bis(phenylthio)buta-1,3-diene synthesis (total reaction time $1 \mathrm{~h}$ at $60^{\circ} \mathrm{C}$ ), and (c) after five cycles of vinyl derivative synthesis (total reaction time is $5 \mathrm{~h}$ at $130^{\circ} \mathrm{C}$ ).

The surface of the CF-nylon reactor before the reaction was smooth (Figure 12a) and consisted of well-defined layers with pores between them. SEM of a cross-section prepared in liquid nitrogen revealed pores in the interior located between the layers. After nucleophilic addition, destruction of the microstructure of the reactor was found: many cracks appeared on the surface, carbon fibers emerged from the plastic (Figure 12b), and expansion of the pores inside was also observed (Figure S9). Despite this, the macrostructure of the reactor remained the same. EDX showed the presence of microcrystals containing potassium, both on the surface and inside the layer (Figures S11, S13 and S14). 
a)
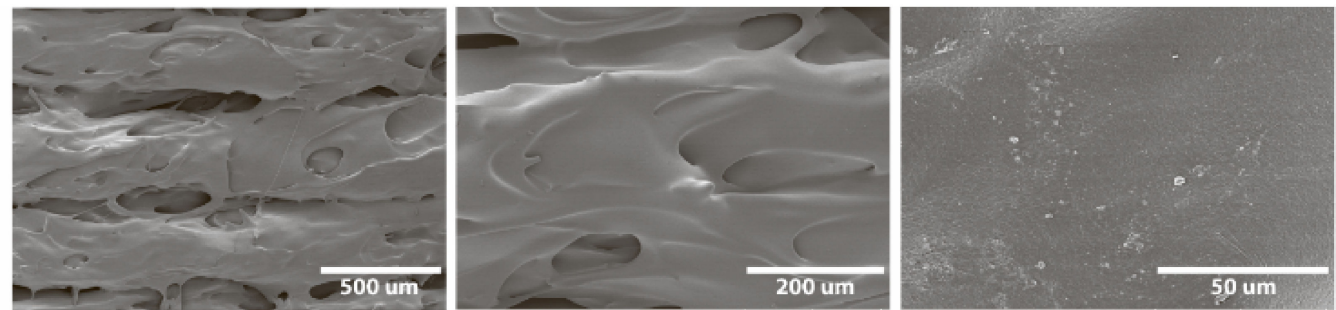

b)
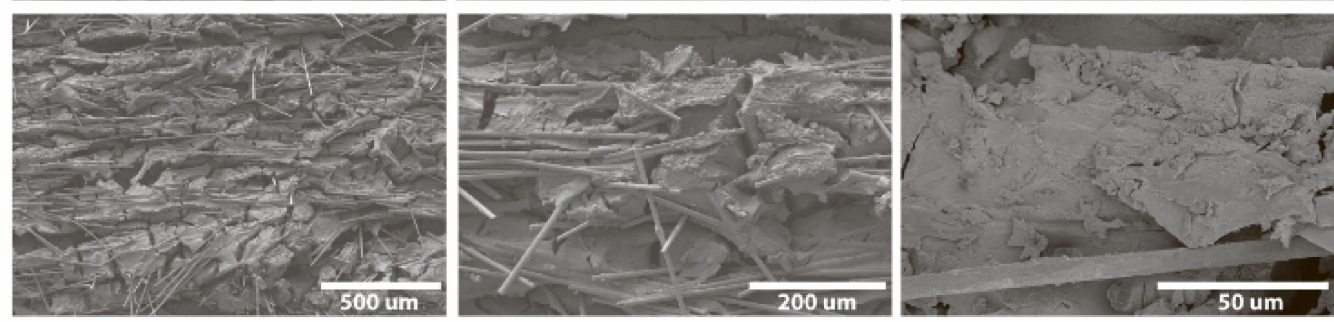

Figure 12. SEM images of the CF-nylon reactor surface at different magnifications: (a) before the reaction and (b) after 7 cycles of vinyl derivative synthesis (total reaction time is $11 \mathrm{~h}$ at $130^{\circ} \mathrm{C}$ ).

\section{Materials and Methods}

General information. Materials used for the research were obtained from commercial sources. Polypropylene (PP, engineering grade, filled with calcium carbonate) was purchased from FL-33. Carbon fiber-reinforced nylon (CF-nylon, engineering grade, commercial name Nylforce Carbon Fiber) was purchased from FiberForce (Fiber Force Italy S.R.L., Treviso, Vicolo del Cristo, 4, Italy). The content of carbon fibers was approximately $20 \%$ by weight. All materials used for additive manufacturing were purchased in the form of filaments with diameters of $1.75 \mathrm{~mm}$. Setting of FFF parameters and G-code was carried out using Simplify3D 3.1.1 software (Simplify3D, LLC, 2016). The parts were 3D printed using a Picaso 3D Designer Pro 250 printer. Reagents were obtained from commercial sources and verified by NMR prior to use. The solvents were purified according to published methods. NMR spectra were recorded on a Bruker Fourier 300 HD (Bruker BioSpin AG, Fällanden, Switzerland) at $300.1 \mathrm{MHz}$ for ${ }^{1} \mathrm{H}$.

Caution. The experimental procedures described in the present study involve the evolution of gaseous acetylene upon the reaction of water with calcium carbide. The necessary safety requirement for experiments with gases, acetylene, and $\mathrm{CaC}_{2}$ should be implemented. Acetylene and hydrogen are flammable and explosive gases, which require the appropriate regulations to be implemented in all experimental work (see corresponding regulations). For all gases involved, care should be taken to avoid an accumulation of exceeding pressure. Normal gas flow should be maintained to avoid gas feeding channel blockage. The reactor should be composed of two parts, with the cap easily removed upon exceeding internal pressure (acting as a pressure release valve). Gas generation processes with the use of the developed reactor described here were optimized for an amount of solid gas precursor of approximately $1-3 \mathrm{~g}$.

$3 D$ printing of the reactors. Reactors were created using a single AM process and were monolithic. The cap was 3D printed separately. Parameters of AM process are given in Table 5. For both materials, infill was performed with a density of $100 \%$ and a grid pattern. PP showed poor adhesion to the build platform, so 3D printing was performed on a $3 \mathrm{~mm}$ polypropylene sheet. In the case of CF-nylon, glue was used for better adhesion to the build platform. Reactors and caps were 3D printed in inverted position relative to Figure 2a without any additional support. After the AM process was completed, the devices were removed from the build platform using a chisel. Gas exhaust holes with diameters of $1 \mathrm{~mm}$ were drilled in the conical extension of the distributor. The upper edge of the acetylene generation chamber and the cap were slightly rasped for better fitting. 
Table 5. Parameters of FFF process.

\begin{tabular}{ccccccc}
\hline Material & $\begin{array}{c}\text { Diameter of } \\
\text { Nozzle, } \mathbf{m m}\end{array}$ & $\begin{array}{c}\text { Temperature of } \\
\text { Build Platform, }^{\circ} \mathbf{C}\end{array}$ & $\begin{array}{c}\text { Temperature of } \\
\text { Nozzle, }{ }^{\circ} \mathbf{C}\end{array}$ & $\begin{array}{c}\text { Cooling } \\
\text { Intensity, } \%\end{array}$ & $\begin{array}{c}\text { Extrusion } \\
\text { Multiplier }\end{array}$ & $\begin{array}{c}\text { Layer Height, } \\
\text { mm }\end{array}$ \\
\hline PP & 0.3 & 80 & 235 & 20 & 0.98 & 0.20 \\
\hline CF-Nylon & 0.5 & 100 & 245 & 60 & 0.80 & 0.35 \\
\hline
\end{tabular}

Analysis of the efficiency of the reactor and drying compartment. DMSO $(15 \mathrm{~mL})$ was added to a polypropylene tube. $\mathrm{CaC}_{2}$ grains $(\sim 2-4 \mathrm{~mm}, 3 \mathrm{~g})$ were added to the acetylene generation chamber, after which a mixture of $4 \mathrm{~mL}$ of DMF and $3 \mathrm{~mL}$ of water was added in two portions at $10 \mathrm{~min}$ intervals. The reactor was closed with a cap (covered with silicone grease) and placed in the tube. After $20 \mathrm{~min}$ of gas bubbling through the solvent at room temperature, the concentration of acetylene in DMSO was determined by ${ }^{1} \mathrm{H} N M R$ spectroscopy using trimethyl(phenyl)silane as an internal standard. In experiments to assess the efficiency of drying the resulting gas with a drying compartment, the concentration of water in DMSO was measured using a Mettler Toledo C10S coulometric Karl Fischer titrator.

Chemical reaction: nucleophilic addition to acetylene. DMSO $(30 \mathrm{~mL})$, an appropriate substrate $(7.7 \mathrm{mmol})$, potassium fluoride $(9.2 \mathrm{mmol}, 537 \mathrm{mg})$, and potassium hydroxide $(9.2 \mathrm{mmol}, 518 \mathrm{mg}$ ) were added to a glass flask (volume $50 \mathrm{~mL}$ and 29 joints). Then, the reactor was placed in a flask. $\mathrm{CaC}_{2}$ powder $(23 \mathrm{mmol}, 1.47 \mathrm{~g})$ and DMSO $(2 \mathrm{~mL})$ were added to the acetylene generation chamber. The reactor was closed with a cap (covered with silicone grease). The reaction mixture was stirred for $5 \mathrm{~min}$ and heated for the required time at the appropriate temperature (Table 4 ). Then, $2 \mathrm{~mL}$ of water was added slowly dropwise (over $5 \mathrm{~min}$ ) through the rubber-sealed hole in the cap of the reactor using a syringe. Gas evolution was usually observed after adding $0.5-1 \mathrm{~mL}$ of water. Photo of reaction setup is given in Figure 13a. After the reaction, the mixture was diluted with a deuterated solvent, and the conversion was measured by ${ }^{1} \mathrm{H}$ NMR.

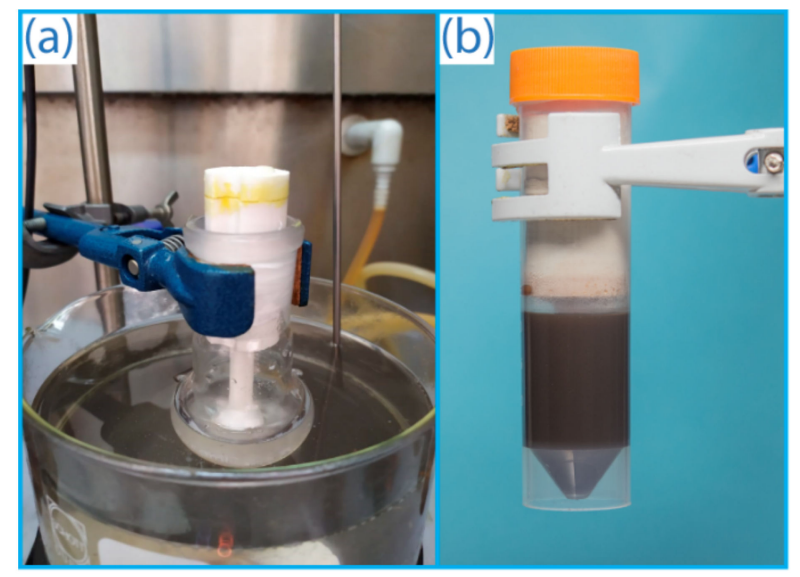

Figure 13. Photos of reaction setups for syntheses of (a) vinyl derivatives and (b) 1,4-bis(arylthio)buta1,3-dienes.

Chemical reaction: Ni-catalyzed addition of diaryl disulfides to acetylene leading to selective 1,4-bis(arylthio)buta-1,3-dienes formation. The threaded neck of the polypropylene tube was wrapped with PTFE tape. The tube was flushed with argon. Ni(acac) $2\left(3 \times 10^{-2} \mathrm{mmol}\right.$, $7.7 \mathrm{mg}$ ) was added to the tube and dissolved in DMF $(15 \mathrm{~mL}) . \mathrm{CaC}_{2}$ grains $(\sim 2-4 \mathrm{~mm}$, $3 \mathrm{~g})$ were added to the acetylene generation chamber, and then DMF $(4 \mathrm{~mL})$ and water $(3 \mathrm{~mL})$ were added. The reactor was immediately closed with a cap (covered with silicone grease) and placed in a polypropylene tube with $\mathrm{Ni}(\mathrm{acac})_{2}$ solution. The tube with the reactor was placed in a water ice bath. $\mathrm{PPhCy}_{2}\left(3 \times 10^{-1} \mathrm{mmol}, 82.2 \mathrm{mg}\right)$ and $\mathrm{Ar}_{2} \mathrm{~S}_{2}$ $(1 \mathrm{mmol})$ were dissolved together in DMF $(1 \mathrm{~mL})$. After $20 \mathrm{~min}$ of bubbling acetylene, 
a solution of disulfide and phosphine was added to the tube, and the reactor cap was removed. The tube was closed and heated at $60^{\circ} \mathrm{C}$ for $1 \mathrm{~h}$. Photo of reaction setup is given in Figure 13b. No stirring was applied. The open reactor remained in the polypropylene tube during the reaction. After completion of the reaction, the solvent was evaporated on a rotary evaporator, and the product was purified by flash chromatography on silica gel 60 $(0.15-0.40 \mathrm{~mm})$ eluting with a hexane $/ \mathrm{CH}_{2} \mathrm{Cl}_{2}$ gradient. Products were identified by NMR according to literature data [80]. The purity of isolated products was over $98 \%$.

Chemical reaction: Ni-catalyzed addition of diaryl disulfides to acetylene leading to selective 1,2-bis(arylthio)ethene formation. The tube was flushed with argon. $\mathrm{CaC}_{2}$ grains $(\sim 2-4 \mathrm{~mm}$, $3 \mathrm{~g}$ ) were added to the acetylene generation chamber, followed by the addition of a mixture of DMF $(2 \mathrm{~mL})$ and water $(1.5 \mathrm{~mL})$. The reactor was immediately closed and placed in a tube with $\mathrm{MeCN}$. The tube with the reactor was placed in a water ice bath. After $15 \mathrm{~min}$, another portion of a mixture of DMF $(2 \mathrm{~mL})$ and water $(3.5 \mathrm{~mL})$ was added. Solid reagents including $\mathrm{Ar}_{2} \mathrm{~S}_{2}(1 \mathrm{mmol}), \mathrm{Ni}(\mathrm{acac})_{2}\left(3 \times 10^{-2} \mathrm{mmol}, 7.7 \mathrm{mg}\right)$ and $\mathrm{PPh}_{3}\left(3 \times 10^{-1} \mathrm{mmol}\right.$, $78.7 \mathrm{mg}$ ) were added to a screw-capped tube. After $45 \mathrm{~min}$ of bubbling acetylene, the reactor was removed, and pre-saturated $\mathrm{MeCN}(5 \mathrm{~mL})$ was added to the solid reagents. The tube was immediately closed. The reaction was carried out at $60^{\circ} \mathrm{C}$ with stirring for $48 \mathrm{~h}$. After completion of the reaction, the solvent was evaporated on a rotary evaporator, and the product was purified by flash chromatography on silica gel $60(0.15-0.40 \mathrm{~mm})$ eluting with a hexane $/ \mathrm{CH}_{2} \mathrm{Cl}_{2}$ gradient. Products were identified by NMR according to the literature data [80]. The purity of isolated products was over $98 \%$.

Chemical reaction: carboxylation of Grignard reagent. A solution of n-butyl magnesium bromide in THF $(0.7 \mathrm{~mol} / 1,7.5 \mathrm{~mL})$ was diluted with THF $(25 \mathrm{~mL})$ in a two-neck flask (50 $\mathrm{mL}$ volume) in a stream of argon. The flask was closed with a rubber septum and placed in a water ice bath. $\mathrm{NaHCO}_{3}$ powder $(3 \mathrm{~g})$ was added to the gas generation chamber of a PP reactor without a neck (Figure $4 \mathrm{~d}$ ). The reactor was closed with a cap (treated with silicone grease) and connected to the flask via a needle. Then, an aqueous solution of sulfuric acid ( $25 \mathrm{wt}$. \%, $6 \mathrm{~mL}$ ) was slowly added dropwise (for $1 \mathrm{~h}$ ) through the rubber-sealed hole using a syringe pump. The reaction was conducted under stirring. Then ice $(30 \mathrm{~g})$ was added, followed by dropwise addition of an aqueous solution of $\mathrm{HCl}(18 \mathrm{wt} . \%, 20 \mathrm{~mL})$. The product was extracted with diethyl ether $(3 \times 50 \mathrm{~mL})$ and dried under $\mathrm{Na}_{2} \mathrm{SO}_{4}$. To obtain the pure product, the solvent was removed on a rotary evaporator.

Chemical reaction: hydrogenation of alkene. Unreduced 5\% Pd/C (267 mg), PhH (40 mL), and ethyl cinnamate $(2.5 \mathrm{mmol}, 441 \mathrm{mg}$ ) were added to a flask ( $50 \mathrm{~mL}$ volume with 29 joints). The reaction mixture was stirred for $5 \mathrm{~min}$ and heated at $50^{\circ} \mathrm{C}$. Zn grains $(2 \mathrm{~g})$ were added to the gas generation chamber of the PP reactor followed by a single addition of an aqueous solution of sulfuric acid $(30 \mathrm{wt}$. $\%, 6 \mathrm{~mL}$ ). The reactor was closed with a cap (covered with silicone grease) and placed in the flask. The reaction was conducted for $90 \mathrm{~min}$ under stirring and heating at the appropriate temperature. Gas evolution was continued for $1.5 \mathrm{~h}$. Then, the reaction mixture was removed from the gas generation chamber, and new portions of $\mathrm{Zn}$ and sulfuric acid were added. The reaction was carried out for an additional $90 \mathrm{~min}$. The reaction mixture was then cooled to room temperature and filtered through a pad of celite. To obtain a pure product, the solvent was removed on a rotary evaporator.

Chemical reaction: nucleophilic addition to deuterated acetylene. DMSO-d6 $(7 \mathrm{~mL})$, an appropriate substrate $(1 \mathrm{mmol}), \mathrm{KOH}(2 \mathrm{mmol}, 112 \mathrm{mg})$, and $\mathrm{KF}(1 \mathrm{mmol}, 58 \mathrm{mg})$ were placed in a flask (50 mL volume with 29 joints) with a stirrer. $\mathrm{CaC}_{2}$ powder $(1.5 \mathrm{~g})$ and DMSO-d6 $(2 \mathrm{~mL})$ were added to the gas generation chamber of the PP reactor. The reaction mixture was heated at $120^{\circ} \mathrm{C}$ for $5 \mathrm{~min}$, and then $2 \mathrm{~mL}$ of $\mathrm{D}_{2} \mathrm{O}$ was slowly added dropwise (over $5 \mathrm{~min}$ ) through the rubber-sealed hole in the cap of the reactor using a syringe. After complete addition of $\mathrm{D}_{2} \mathrm{O}$, the solution in the flask was stirred at $120^{\circ} \mathrm{C}$ for $2 \mathrm{~h}$. Upon completion of stirring, the flask was removed from the bath and cooled to room temperature. The resulting vinyl ether was extracted from the reaction mixture with hexane $(3 \times 10 \mathrm{~mL})$. The product was purified using column chromatography (silica gel 60 
$(0.015-0.040 \mathrm{~mm})$, hexane as the eluent). Then, the solvent was removed under reduced pressure. Products were identified by NMR. The purity of isolated products was over $98 \%$.

Chemical reaction: Ni-catalyzed addition of diaryl disulfides to deuterated acetylene leading to selective 1,2-bis(arylthio)ethene formation. The screw-capped tube was flushed with argon. Solid reagents including $\mathrm{Ar}_{2} \mathrm{~S}_{2}\left(2 \times 10^{-1} \mathrm{mmol}\right), \mathrm{Ni}(\mathrm{acac})_{2}\left(6 \times 10^{-3} \mathrm{mmol}, 1.5 \mathrm{mg}\right)$, and $\mathrm{PPh}_{3}\left(6 \times 10^{-2} \mathrm{mmol}, 15.7 \mathrm{mg}\right)$ were added to the tube. MeCN-d3 was presaturated with deuterated acetylene using the reactor. For this, $\mathrm{CaC}_{2}$ powder $(1.5 \mathrm{~g})$ was added to the acetylene generation chamber, followed by the addition of DMSO-d6 $(2 \mathrm{~mL})$. The reactor was closed. $\mathrm{D}_{2} \mathrm{O}(2 \mathrm{~mL})$ was slowly added dropwise (over $30 \mathrm{~min}$ ) through the rubber-sealed hole in the cap of the reactor using a syringe. After 30 min of bubbling $\mathrm{C}_{2} \mathrm{D}_{2}$ through MeCN-d3 in a water ice bath, pre-saturated MeCN-d3 $(1 \mathrm{~mL})$ was added to the solid reagents. The tube was immediately closed. The reaction was carried out at $60^{\circ} \mathrm{C}$ with stirring for $48 \mathrm{~h}$. After completion of the reaction, the solvent was evaporated on a rotary evaporator, and the product was purified by flash chromatography on silica gel 60 $(0.15-0.40 \mathrm{~mm})$ eluting with a hexane $/ \mathrm{CH}_{2} \mathrm{Cl}_{2}$ gradient. Products were identified by NMR. The purity of isolated products was over $98 \%$.

Chemical reaction: deuteration of alkene. Unreduced 5\% Pd/C (267 mg), $\mathrm{PhH}(40 \mathrm{~mL})$, and ethyl cinnamate ( $2.5 \mathrm{mmol}, 441 \mathrm{mg}$ ) were added to a flask ( $50 \mathrm{~mL}$ volume with 29 joints). The reaction mixture was stirred for $5 \mathrm{~min}$ and heated at $50{ }^{\circ} \mathrm{C}$. Zn grains $(2 \mathrm{~g})$ were added to the gas generation chamber of the PP reactor followed by a single addition of a solution of $\mathrm{D}_{2} \mathrm{SO}_{4}$ in $\mathrm{D}_{2} \mathrm{O}$ (30 wt. $\%, 6 \mathrm{~mL}$ ). The reactor was closed with a cap (covered with silicone grease) and placed in the flask. The reaction was conducted for 90 min under stirring and heating at $50^{\circ} \mathrm{C}$. Then, the reaction mixture was removed from the gas generation chamber, and new portions of $\mathrm{Zn}$ and sulfuric acid were added. The reaction was carried out for an additional $90 \mathrm{~min}$. Then, the reaction solution was removed from the gas generation chamber, filtered, and added back. The reaction was continued for another $12 \mathrm{~h}$. After the reaction, the conversion and ${ }^{2} \mathrm{D}$ incorporation were measured by ${ }^{1} \mathrm{H}$ NMR.

Electron microscopy SEM and EDX studies. Plastic reactors after the reactions were washed with acetone or isopropyl alcohol. The samples were mounted on a $15 \mathrm{~mm}$ aluminum specimen stub and fixed by carbon double-sided adhesive tape. Metal coating with a thin film $(10 \mathrm{~nm})$ of a platinum/palladium alloy $(80 / 20)$ was performed by using a magnetron sputtering method as described earlier [94]. The observations were carried out using a Hitachi SU8000 field-emission scanning electron microscope (FE-SEM). Images were acquired in secondary electron mode at a $2 \mathrm{kV}$ accelerating voltage and at a working distance of $8-10 \mathrm{~mm}$. The morphology of the samples was studied taking into account the possible influence of the metal coating on the surface. EDX-SEM studies were carried out using an X-ray spectrometer Oxford Instruments X-Max 80.

Sample cross-section preparation for SEM and EDX. The analyzed part of the reactor 3D printed with CF-nylon was dried at $70{ }^{\circ} \mathrm{C}$ for $2 \mathrm{~h}$. Then, it was frozen in liquid nitrogen, followed by cutting with a knife immediately after being extracted from liquid nitrogen.

\section{Conclusions}

In common chemical practice, handling dangerous gases is highly complicated for several reasons. This work greatly expands the possibilities of involving gaseous reactants in chemical transformations using a $3 \mathrm{D}$ printed reactor. Additive manufacturing allows for the creation of reactors of various shapes to increase the efficiency of synthesis. A variety of materials for FFF printing allow for the optimal material to be chosen for specific purposes and tasks. In this work, we developed a compact reactor for the on-demand production of acetylene, $\mathrm{H}_{2}$, and $\mathrm{CO}_{2}$ that avoids contamination of the reaction solution with components of reaction of $\mathrm{CaC}_{2}$ with water. The absence of joints minimizes the risks of uncontrolled leakage and loss of acetylene. The reactor was $3 \mathrm{D}$ printed with commercially available industrial materials-polypropylene and CF-nylon. The versatility of the design of the reactor lies in the possibility of its use in combination with vessels of various shapes and sizes. The geometrical parameters of the reactor and shape of the distributor, as well as 
the number of gas exhaust holes, are adjustable parameters, which, if necessary, can be changed to better match the shape of the vessel. Moreover, possibilities of integrating gas-drying and flow meter capabilities were shown.

The applicability and versatility of the proposed reactor was demonstrated in the reaction of nucleophilic addition of alcohols, amines, and thiols to acetylene, as well as in reactions of Ni-catalyzed synthesis of 1,4-bis(arylthio)buta-1,3-dienes and 1,2-bis(arylthio)ethenes. In the first case, the reactor was used in combination with a flask, and in the second, in combination with a test tube. In the synthesis of 1,4-bis(arylthio)buta-1,3-dienes, the reactor remained in a test tube during the reaction to provide an additional acetylene pressure. It was shown that the use of the reactor makes it possible to carry out syntheses with the participation of acetylene in high yields.

The reusability of the reactor was demonstrated in the reaction of nucleophilic addition to acetylene. Despite the harsh conditions, the 3D printed reactor with CF-nylon withstood nine reaction cycles without loss of yield. The polypropylene reactor was more stable and was used 15 times without mechanical damage. This greatly facilitates the maintenance of long-term processes and allows for the reactors to be changed one after the other. Using SEM, it was shown that in the case of CF-nylon, the microstructure of the reactor is susceptible to destruction under such drastic conditions, while the microstructure of the PP reactor does not change.

The safety of acetylene-based synthesis using the described technology is significantly improved due to immediate acetylene consumption without acetylene accumulation under increased pressure. The solid source of acetylene, $\mathrm{CaC}_{2}$, is a cheap industrially produced reagent that is convenient for practical usage and easy to dose and handle.

One of the advantages of the developed reactor is its versatility for producing other gases, which is shown with examples of the formation of $\mathrm{CO}_{2}$ and $\mathrm{H}_{2}$ followed by carboxylation and hydrogenation reactions, respectively. Importantly, one of the most important applications of the reactor is in the generation of deuterated acetylene and $D_{2}$, which enables atom-economic and cost-efficient deuterium labeling of organic molecules.

Thus, the proposed approach opens up new opportunities for many synthetic laboratories working with gaseous reagents to prepare functionalized organic molecules and further access to biologically active molecules as well as for chemical engineering and educational purposes.

Supplementary Materials: Supplementary materials can be found at https://www.mdpi.com/ article/10.3390/ijms22189919/s1.

Author Contributions: K.S.E. performed optimization of FFF parameters, analysis of efficiency of the reactor and of drying compartment, Ni-catalyzed addition to $\mathrm{C}_{2} \mathrm{H}_{2}$ and $\mathrm{C}_{2} \mathrm{D}_{2}$, reactions with $\mathrm{CO}_{2}$, $\mathrm{H}_{2}$, and $\mathrm{D}_{2}$, as well as electron microscopy; E.G.G. developed the design of the reactor and carried out 3D printing; D.E.S. and K.S.R. performed nucleophilic addition to $\mathrm{C}_{2} \mathrm{H}_{2}$ and $\mathrm{C}_{2} \mathrm{D}_{2}$, as well as analysis of reusability of the reactor; V.P.A. designed the concept, guided the research, and supervised the project. All authors discussed the results, analyzed data, and took part in the manuscript preparation. All authors have read and agreed to the published version of the manuscript.

Funding: The study on 3D printing, reactor design, and Ni catalysis was supported by the Russian Science Foundation (grant 19-13-00460). K.S.R. and S.D.E. thank SPbU (Pure ID: 72776812) for supporting research on vinylation reactions.

Institutional Review Board Statement: Not applicable.

Informed Consent Statement: Not applicable.

Data Availability Statement: Data are contained in the article and Supplementary Materials.

Conflicts of Interest: The authors declare that they have no known competing financial interests or personal relationships that could have appeared to influence the work reported in this paper. 


\section{References}

1. Semina, E.; Tuzina, P.; Bienewald, F.; Hashmi, A.S.K.; Schaub, T. Ruthenium-catalyzed synthesis of vinylamides at low acetylene pressure. Chem. Commun. 2020, 56, 5977-5980. [CrossRef] [PubMed]

2. Lin, T.J.; Xie, H.; Meng, X.; Shi, L. Characterization and catalytic application of $\mathrm{Bi}_{2} \mathrm{O}_{3} / \mathrm{NiO}$ composite oxides in the Reppe carbonylation to acrylic acid. Catal. Commun. 2015, 68, 88-92. [CrossRef]

3. Cui, L.; Yang, X.; Zeng, Y.; Chen, Y.; Wang, G. A unique nickel-base nitrogen-oxygen bidentate ligand catalyst for carbonylation of acetylene to acrylic acid. Mol. Catal. 2019, 468, 57-61. [CrossRef]

4. Ivanov, A.V.; Shcherbakova, V.S.; Ushakov, I.A.; Sobenina, L.N.; Petrova, O.V.; Mikhaleva, A.I.; Trofimov, B.A. 2-(1Hydroxypropyn-2-yl)-1-vinylpyrroles: The first successful Favorsky ethynylation of pyrrolecarbaldehydes. Beilstein J. Org. Chem. 2015, 11, 228-232. [CrossRef] [PubMed]

5. Matake, R.; Niwa, Y.; Matsubara, H. Phase-Vanishing Method with Acetylene Evolution and Its Utilization in Several Organic Syntheses. Org. Lett. 2015, 17, 2354-2357. [CrossRef] [PubMed]

6. Trotuş, I.-T.; Zimmermann, T.; Schüth, F. Catalytic Reactions of Acetylene: A Feedstock for the Chemical Industry Revisited. Chem. Rev. 2014, 114, 1761-1782. [CrossRef]

7. Stang, P.J.; Diederich, F. Modern Acetylene Chemistry; Wiley: Weinheim, Germany, 2008; pp. 1-527. ISBN 9783527615278.

8. Diederich, F.; Stang, P.J.; Tykwinski, R.R. Acetylene Chemistry. Chemistry, Biology, and Material Science; Wiley: Weinheim, Germany, 2005; pp. 1-528. ISBN 9783527307814.

9. Voronin, V.V.; Ledovskaya, M.S.; Bogachenkov, A.S.; Rodygin, K.S.; Ananikov, V.P. Acetylene in Organic Synthesis: Recent Progress and New Uses. Molecules 2018, 23, 2442. [CrossRef]

10. Pässler, P.; Hefner, W.; Buckl, K.; Meinass, H.; Meiswinkel, A.; Wernicke, H.-J.; Ebersberg, G.; Müller, R.; Bässler, J.; Behringer, H.; et al. Acetylene. In Ullmann's Encyclopedia of Industrial Chemistry, 4th ed.; Wiley: Weinheim, Germany, 2011; pp. 277-326. ISBN 9783527306732.

11. Feng, X.; Huang, X.; Ma, Y.; Song, G.; Li, H. New Structural Carbons via Industrial Gas Explosion for Hybrid Cathodes in Li-S Batteries. ACS Sustain. Chem. Eng. 2019, 7, 12948-12954. [CrossRef]

12. Huang, H.; Deng, J.; Shi, Y. Optically Active Physical Gels with Chiral Memory Ability: Directly Prepared by Helix-Sense-Selective Polymerization. Macromolecules 2016, 49, 2948-2956. [CrossRef]

13. King, A.O.; Larsen, R.D.; Negishi, E.-I. Palladium-Catalyzed Heterogeneous Hydrogenation. In Handbook of Organopalladium Chemistry for Organic Synthesis; Negishi, E.-I., Ed.; Wiley: New York, NY, USA, 2005; pp. 2719-2752.

14. Zhang, Z.; Butt, N.A.; Zhang, W. Asymmetric Hydrogenation of Nonaromatic Cyclic Substrates. Chem. Rev. 2016, 116, 14769-14827. [CrossRef]

15. Margarita, C.; Rabten, W.; Andersson, P.G. Transition-Metal-Catalyzed Regioselective Asymmetric Mono-Hydrogenation of Dienes and Polyenes. Chem. Eur. J. 2018, 24, 8022-8028. [CrossRef]

16. Liu, Q.; Wu, L.; Jackstell, R.; Beller, M. Using carbon dioxide as a building block in organic synthesis. Nat. Commun. 2015, 6, 5933. [CrossRef]

17. Dabral, S.; Schaub, T. The Use of Carbon Dioxide $\left(\mathrm{CO}_{2}\right)$ as a Building Block in Organic Synthesis from an Industrial Perspective. Adv. Synth. Catal. 2019, 361, 223-246. [CrossRef]

18. Tortajada, A.; Juliá-Hernández, F.; Börjesson, M.; Moragas, T.; Martin, R. Transition-Metal-Catalyzed Carboxylation Reactions with Carbon Dioxide. Angew. Chem. Int. Ed. 2018, 57, 15948-15982. [CrossRef]

19. Pradhan, S.; Roy, S.; Sahoo, B.; Chatterjee, I. Utilization of $\mathrm{CO}_{2}$ Feedstock for Organic Synthesis by Visible-Light Photoredox Catalysis. Chem. Eur. J. 2021, 27, 2254-2269. [CrossRef]

20. Hosseini, A.; Schreiner, P.R. Direct Exploitation of the Ethynyl Moiety in Calcium Carbide through Sealed Ball Milling. Eur. J. Org. Chem. 2020, 2020, 4339-4346. [CrossRef]

21. Hosseini, A.; Schreiner, P.R. Synthesis of Exclusively 4-Substituted $\beta$-Lactams through the Kinugasa Reaction Utilizing Calcium Carbide. Org. Lett. 2019, 21, 3746-3749. [CrossRef] [PubMed]

22. Zhang, Q.; Yuan, H.-Y.; Lin, X.-T.; Fukaya, N.; Fujitani, T.; Sato, K.; Choi, J.-C. Calcium carbide as a dehydrating agent for the synthesis of carbamates, glycerol carbonate, and cyclic carbonates from carbon dioxide. Green Chem. 2020, 22, 4231-4239. [CrossRef]

23. Li, D.; Qiu, S.; Chen, Y.; Wu, L. $\mathrm{K}_{2} \mathrm{CO}_{3}$-Promoted Pyrazoles Synthesis from 1,3-Dipolar Cycloaddition of N-Tosylhydrazones with Acetylene Gas. ChemistrySelect 2020, 5, 12034-12037. [CrossRef]

24. Gao, L.; Li, Z. Direct Synthesis of 1-Arylprop-1-ynes with Calcium Carbide as an Acetylene Source. Synlett 2019, 30, 1580-1584. [CrossRef]

25. Yu, Y.; Huang, W.; Chen, Y.; Gao, B.; Wu, W.; Jiang, H. Calcium carbide as the acetylide source: Transition-metal-free synthesis of substituted pyrazoles via [1,5]-sigmatropic rearrangements. Green Chem. 2016, 18, 6445-6449. [CrossRef]

26. Gao, L.; Li, Z. Synthesis of aromatic terminal allenes and aliphatic terminal alkynes from hydrazones using calcium carbide as an acetylene source. Org. Chem. Front. 2020, 7, 702-708. [CrossRef]

27. Teong, S.P.; Yu, D.; Sum, Y.N.; Zhang, Y. Copper catalysed alkynylation of tertiary amines with $\mathrm{CaC}_{2}$ via $\mathrm{sp}^{3} \mathrm{C}-\mathrm{H}$ activation. Green Chem. 2016, 18, 3499-3502. [CrossRef]

28. Fu, R.; Li, Z. Direct Synthesis of Symmetric Diarylethynes from Calcium Carbide and Arylboronic Acids/Esters. Eur. J. Org. Chem. 2017, 2017, 6648-6651. [CrossRef] 
29. Fu, R.; Li, Z. N-Propargylation of secondary amines directly using calcium carbide as an acetylene source. J. Chem. Res. 2017, 41, 341-345. [CrossRef]

30. Fu, R.; Li, Z. Direct Synthesis of 2-Methylbenzofurans from Calcium Carbide and Salicylaldehyde p-Tosylhydrazones. Org. Lett. 2018, 20, 2342-2345. [CrossRef]

31. Li, Z.; He, L.; Fu, R.; Song, G.; Song, W.; Xie, D.; Yang, J. One-step construction of saturated six-membered rings directly using calcium carbide as an acetylene source: Synthesis of 1,3,5-triaroylcyclohexanes. Tetrahedron 2016, 72, 4321-4328. [CrossRef]

32. Kaewchangwat, N.; Sukato, R.; Vchirawongkwin, V.; Vilaivan, T.; Sukwattanasinitt, M.; Wacharasindhu, S. Direct synthesis of aryl substituted pyrroles from calcium carbide: An underestimated chemical feedstock. Green Chem. 2015, 17, 460-465. [CrossRef]

33. Rattanangkool, E.; Vilaivan, T.; Sukwattanasinitt, M.; Wacharasindhu, S. An Atom-Economic Approach for Vinylation of Indoles and Phenols Using Calcium Carbide as Acetylene Surrogate. Eur. J. Org. Chem. 2016, 2016, 4347-4353. [CrossRef]

34. Van Beek, W.E.; Gadde, K.; Tehrani, K.A. The Use of Calcium Carbide as Acetylene Source in a Three-Component Coupling with $\omega$-Chlorinated Ketones and Primary Amines. Chem. Eur. J. 2018, 24, 16645-16651. [CrossRef]

35. Rodygin, K.S.; Lotsman, K.A.; Ananikov, V.P. Calcium Carbide Looping System for Acetaldehyde Manufacturing from Virtually any Carbon Source. ChemSusChem 2020, 13, 3679-3685. [CrossRef]

36. Ledovskaya, M.S.; Voronin, V.V.; Rodygin, K.S.; Posvyatenko, A.V.; Egorova, K.S.; Ananikov, V.P. Direct Synthesis of DeuteriumLabeled O-, S-, N-Vinyl Derivatives from Calcium Carbide. Synthesis 2019, 51, 3001-3013. [CrossRef]

37. Voronin, V.V.; Ledovskaya, M.S.; Rodygin, K.S.; Ananikov, V.P. Examining the vinyl moiety as a protecting group for hydroxyl $(-\mathrm{OH})$ functionality under basic conditions. Org. Chem. Front. 2020, 7, 1334-1342. [CrossRef]

38. Rodygin, K.S.; Ledovskaya, M.S.; Voronin, V.V.; Lotsman, K.A.; Ananikov, V.P. Calcium Carbide: Versatile Synthetic Applications, Green Methodology and Sustainability. Eur. J. Org. Chem. 2021, 2021, 43-52. [CrossRef]

39. Kang, H.-W.; Lee, S.J.; Ko, I.K.; Kengla, C.; Yoo, J.J.; Atala, A. A 3D bioprinting system to produce human-scale tissue constructs with structural integrity. Nat. Biotechnol. 2016, 34, 312-319. [CrossRef]

40. Domsta, V.; Seidlitz, A. 3D-Printing of Drug-Eluting Implants: An Overview of the Current Developments Described in the Literature. Molecules 2021, 26, 4066. [CrossRef] [PubMed]

41. Murphy, S.V.; Atala, A. 3D bioprinting of tissues and organs. Nat. Biotechnol. 2014, 32, 773-785. [CrossRef]

42. Roulon, S.; Soulairol, I.; Cazes, M.; Lemierre, L.; Payre, N.; Delbreilh, L.; Alié, J. D-Sorbitol Physical Properties Effects on Filaments Used by 3D Printing Process for Personalized Medicine. Molecules 2021, 26, 3000. [CrossRef] [PubMed]

43. Chen, Y.; Xiong, X.; Liu, X.; Cui, R.; Wang, C.; Zhao, G.; Zhi, W.; Lu, M.; Duan, K.; Weng, J.; et al. 3D Bioprinting of shear-thinning hybrid bioinks with excellent bioactivity derived from gellan/alginate and thixotropic magnesium phosphate-based gels. J. Mater. Chem. B 2020, 8, 5500-5514. [CrossRef] [PubMed]

44. Gao, G.; Huang, Y.; Schilling, A.F.; Hubbell, K.; Cui, X. Organ Bioprinting: Are We There Yet? Adv. Healthc. Mater. 2018, 7, 1701018. [CrossRef]

45. Zolfagharian, A.; Mahmud, M.A.P.; Gharaie, S.; Bodaghi, M.; Kouzani, A.Z.; Kaynak, A. 3D/4D-printed bending-type soft pneumatic actuators: Fabrication, modelling, and control. Virtual Phys. Prototyp. 2020, 15, 373-402. [CrossRef]

46. Yap, Y.L.; Sing, S.L.; Yeong, W.Y. A review of 3D printing processes and materials for soft robotics. Rapid Prototyp. J. 2020, 26, 1345-1361. [CrossRef]

47. Thakkar, H.; Lawson, S.; Rownaghi, A.A.; Rezaei, F. Development of 3D-printed polymer-zeolite composite monoliths for gas separation. Chem. Eng. J. 2018, 348, 109-116. [CrossRef]

48. Nadgorny, M.; Collins, J.; Xiao, Z.; Scales, P.J.; Connal, L.A. 3D-printing of dynamic self-healing cryogels with tuneable properties. Polym. Chem. 2018, 9, 1684-1692. [CrossRef]

49. Maturi, M.; Pulignani, C.; Locatelli, E.; Buratti, V.V.; Tortorella, S.; Sambri, L.; Franchini, M.C. Phosphorescent bio-based resin for digital light processing (DLP) 3D-printing. Green Chem. 2020, 22, 6212-6224. [CrossRef]

50. Couck, S.; Lefevere, J.; Mullens, S.; Protasova, L.; Meynen, V.; Desmet, G.; Baron, G.V.; Denayer, J.F.M. $\mathrm{CO}_{2}, \mathrm{CH}_{4}$ and $\mathrm{N}_{2}$ separation with a 3DFD-printed ZSM-5 monolith. Chem. Eng. J. 2017, 308, 719-726. [CrossRef]

51. Pudkon, W.; Laomeephol, C.; Damrongsakkul, S.; Kanokpanont, S.; Ratanavaraporn, J. Comparative Study of Silk Fibroin-Based Hydrogels and Their Potential as Material for 3-Dimensional (3D) Printing. Molecules 2021, 26, 3887. [CrossRef] [PubMed]

52. Singh, M.; Haring, A.P.; Tong, Y.; Cesewski, E.; Ball, E.; Jasper, R.; Davis, E.M.; Johnson, B.N. Additive Manufacturing of Mechanically Isotropic Thin Films and Membranes via Microextrusion 3D Printing of Polymer Solutions. ACS Appl. Mater. Interfaces 2019, 11, 6652-6661. [CrossRef]

53. Bas, O.; Lucarotti, S.; Angella, D.D.; Castro, N.J.; Meinert, C.; Wunner, F.M.; Rank, E.; Vozzi, G.; Klein, T.J.; Catelas, I.; et al. Rational design and fabrication of multiphasic soft network composites for tissue engineering articular cartilage: A numerical model-based approach. Chem. Eng. J. 2018, 340, 15-23. [CrossRef]

54. Kestila, A.; Nordling, K.; Miikkulainen, V.; Kaipio, M.; Tikka, T.; Salmi, M.; Auer, A.; Leskelä, M.; Ritala, M. Towards space-grade 3D-printed, ALD-coated small satellite propulsion components for fluidics. Addit. Manuf. 2018, 22, 31-37. [CrossRef]

55. Zhang, C.; Wang, S.; Li, J.; Zhu, Y.; Peng, T.; Yang, H. Additive manufacturing of products with functional fluid channels: A review. Addit. Manuf. 2020, 36, 101490. [CrossRef]

56. Femmer, T.; Flack, I.; Wessling, M. Additive Manufacturing in Fluid Process Engineering. Chem. Ing. Tech. 2016, 88, 535-552. [CrossRef] 
57. Kitson, P.J.; Glatzel, S.; Chen, W.; Lin, C.-G.; Song, Y.-F.; Cronin, L. 3D printing of versatile reactionware for chemical synthesis. Nat. Protoc. 2016, 11, 920-936. [CrossRef] [PubMed]

58. Rossi, S.; Porta, R.; Brenna, D.; Puglisi, A.; Benaglia, M. Stereoselective Catalytic Synthesis of Active Pharmaceutical Ingredients in Homemade 3D-Printed Mesoreactors. Angew. Chem. Int. Ed. 2017, 56, 4290-4294. [CrossRef]

59. Zalesskiy, S.S.; Shlapakov, N.S.; Ananikov, V.P. Visible light mediated metal-free thiol-yne click reaction. Chem. Sci. 2016, 7 , 6740-6745. [CrossRef] [PubMed]

60. Kitson, P.J.; Marie, G.; Francoia, J.-P.; Zalesskiy, S.S.; Sigerson, R.C.; Mathieson, J.S.; Cronin, L. Digitization of multistep organic synthesis in reactionware for on-demand pharmaceuticals. Science 2018, 359, 314-319. [CrossRef]

61. Capel, A.J.; Wright, A.; Harding, M.J.; Weaver, G.W.; Li, Y.; Harris, R.A.; Edmondson, S.; Goodridge, R.D.; Christie, S.D.R. 3D printed fluidics with embedded analytic functionality for automated reaction optimisation. Beilstein J. Org. Chem. 2017, 13, 111-119. [CrossRef] [PubMed]

62. Chen, L.; Jiang, Y.; Huo, H.; Liu, J.; Li, Y.; Li, C.; Zhang, N.; Wang, J. Metal-organic framework-based composite Ni@MOF as Heterogenous catalyst for ethylene trimerization. Appl. Catal. A Gen. 2020, 594, 117457. [CrossRef]

63. Azuaje, J.; Tubío, C.R.; Escalante, L.; Gómez, M.; Guitián, F.; Coelho, A.; Caamaño, O.; Gil, A.; Sotelo, E. An efficient and recyclable 3D printed $\alpha$-Al $2 \mathrm{O} 3$ catalyst for the multicomponent assembly of bioactive heterocycles. Appl. Catal. A Gen. 2017, 530, 203-210. [CrossRef]

64. Tubío, C.R.; Azuaje, J.; Escalante, L.; Coelho, A.; Guitián, F.; Sotelo, E.; Gil, A. 3D printing of a heterogeneous copper-based catalyst. J. Catal. 2016, 334, 110-115. [CrossRef]

65. Ngo, T.D.; Kashani, A.; Imbalzano, G.; Nguyen, K.T.Q.; Hui, D. Additive manufacturing (3D printing): A review of materials, methods, applications and challenges. Compos. Part B Eng. 2018, 143, 172-196. [CrossRef]

66. Ligon, S.C.; Liska, R.; Stampfl, J.; Gurr, M.; Mülhaupt, R. Polymers for 3D Printing and Customized Additive Manufacturing. Chem. Rev. 2017, 117, 10212-10290. [CrossRef]

67. Peris, E.; Okafor, O.; Kulcinskaja, E.; Goodridge, R.; Luis, S.V.; Garcia-Verdugo, E.; O’Reilly, E.; Sans, V. Tuneable 3D printed bioreactors for transaminations under continuous-flow. Green Chem. 2017, 19, 5345-5349. [CrossRef]

68. Okafor, O.; Robertson, K.; Goodridge, R.; Sans, V. Continuous-flow crystallisation in 3D-printed compact devices. React. Chem. Eng. 2019, 4, 1682-1688. [CrossRef]

69. Mo, Y.; Imbrogno, J.; Zhang, H.; Jensen, K.F. Scalable thin-layer membrane reactor for heterogeneous and homogeneous catalytic gas-liquid reactions. Green Chem. 2018, 20, 3867-3874. [CrossRef]

70. Feng, Y.; Wang, J.; Zhang, H.; Wang, J.; Yang, Y. A 3D-Printed Continuous Flow Platform for the Synthesis of Methylaluminoxane Green Chem. 2021, 23, 4087-4094. [CrossRef]

71. Vijayan, S.; Hashimoto, M. 3D printed fittings and fluidic modules for customizable droplet generators. RSC Adv. 2019, 9, 2822-2828. [CrossRef]

72. Ching, T.; Toh, Y.-C.; Hashimoto, M. Fabrication of Complex 3D Fluidic Networks via Modularized Stereolithography. Adv. Eng. Mater. 2019, 22, 1901109. [CrossRef]

73. Morioka, K.; Sato, H.; Morita, K.; Akihide, H.; Nakajima, H.; Shoji, A.; Yanagida, A. Development of an on-chip sample injection system with a 6-port valve incorporated in a microchip. RSC Adv. 2020, 10, 35848-35855. [CrossRef]

74. Erokhin, K.S.; Gordeev, E.G.; Ananikov, V.P. Revealing interactions of layered polymeric materials at solid-liquid interface for building solvent compatibility charts for 3D printing applications. Sci. Rep. 2019, 9, 20177. [CrossRef]

75. Bertolino, M.; Battegazzore, D.; Arrigo, R.; Frache, A. Designing 3D printable polypropylene: Material and process optimisation through rheology. Addit. Manuf. 2021, 40, 101944. [CrossRef]

76. Vidakis, N.; Petousis, M.; Tzounis, L.; Maniadi, A.; Velidakis, E.; Mountakis, N.; Papageorgiou, D.; Liebscher, M.; Mechtcherine, V. Sustainable Additive Manufacturing: Mechanical Response of Polypropylene over Multiple Recycling Processes. Sustainability 2021, 13, 159. [CrossRef]

77. Vidakis, N.; Petousis, M.; Tzounis, L.; Maniadi, A.; Velidakis, E.; Mountakis, N.; Kechagias, J.D. Sustainable Additive Manufacturing: Mechanical Response of Polyamide 12 over Multiple Recycling Processes. Materials 2021, 14, 466. [CrossRef] [PubMed]

78. Hu, Y.; Ladani, R.B.; Brandt, M.; Li, Y.; Mouritz, A.P. Carbon fibre damage during 3D printing of polymer matrix laminates using the FDM process. Mater. Des. 2021, 205, 109679. [CrossRef]

79. Werner, G.; Rodygin, K.S.; Kostin, A.A.; Gordeev, E.G.; Kashin, A.S.; Ananikov, V.P. A solid acetylene reagent with enhanced reactivity: Fluoride-mediated functionalization of alcohols and phenols. Green Chem. 2017, 19, 3032-3041. [CrossRef]

80. Degtyareva, E.; Erokhin, K.S.; Kashin, A.S.; Ananikov, V.P. Switchable Ni-catalyzed bis-thiolation of acetylene with aryl disulfides as an access to functionalized alkenes and 1,3-dienes. Appl. Catal. A Gen. 2019, 571, 170-179. [CrossRef]

81. Patel, M.; Saunthwal, R.K.; Verma, A.K. Base-Mediated Deuteration of Organic Molecules: A Mechanistic Insight. ACS Omega 2018, 3, 10612-10623. [CrossRef]

82. Park, K.; Matsuda, T.; Yamada, T.; Monguchi, Y.; Sawama, Y.; Doi, N.; Sasai, Y.; Kondo, S.-i.; Sawama, Y.; Sajiki, H. Direct Deuteration of Acrylic and Methacrylic Acid Derivatives Catalyzed by Platinum on Carbon in Deuterium Oxide. Adv. Synth. Catal. 2018, 360, 2303-2307. [CrossRef]

83. Zhou, J.; Hartwig, J.F. Iridium-Catalyzed H/D Exchange at Vinyl Groups without Olefin Isomerization. Angew. Chem. Int. Ed. 2008, 47, 5783-5787. [CrossRef] 
84. Tse, S.K.S.; Xue, P.; Lin, Z.; Jia, G. Hydrogen/Deuterium Exchange Reactions of Olefins with Deuterium Oxide Mediated by the Carbonylchlorohydrido-tris(triphenylphosphine)ruthenium(II) Complex. Adv. Synth. Catal. 2010, 352, 1512-1522. [CrossRef]

85. Hatano, M.; Nishimura, T.; Yorimitsu, H. Selective H/D Exchange at Vinyl and Methylidene Groups with $\mathrm{D}_{2} \mathrm{O}$ Catalyzed by an Iridium Complex. Org. Lett. 2016, 18, 3674-3677. [CrossRef]

86. Erdogan, G.; Grotjahn, D.B. Mild and Selective Deuteration and Isomerization of Alkenes by a Bifunctional Catalyst and Deuterium Oxide. J. Am. Chem. Soc. 2009, 131, 10354-10355. [CrossRef]

87. Yabe, Y.; Sawama, Y.; Monguchi, Y.; Sajiki, H. Site-Selective Deuterated-Alkene Synthesis with Palladium on Boron Nitride. Chem. Eur. J. 2013, 19, 484-488. [CrossRef]

88. Gordillo, Á.; Forigua, J.; López-Mardomingo, C.; de Jesús, E. Stereoselective Synthesis of (E)- and (Z)-Triethoxy(vinyl-d 2 )silanes by Hydrosilylation of Acetylene- $\mathrm{d}_{2}$. Organometallics 2011, 30, 352-355. [CrossRef]

89. Herwig, P.; Zawatzky, K.; Grieser, M.; Heber, O.; Jordon-Thaden, B.; Krantz, C.; Novotny, O.; Repnow, R.; Schurig, V.; Schwalm, D.; et al. Imaging the Absolute Configuration of a Chiral Epoxide in the Gas Phase. Science 2013, 342, 1084-1086. [CrossRef]

90. Kawase, T.; Okada, T.; Enomoto, T.; Kikuchi, T.; Miyake, Y.; Oda, M. Thermal Rearrangement of 2,5-Bis(dicyanomethylene)bicyclo[4.2.0]oct7-ene and 2,5-Bis(dicyanomethylene)bicyclo[4.2.0]octa-3,7-diene. Unexpected Formation of 2,6-Bis(dicyanomethylene)bicyclo[3.3.0]octa1(5)-ene and -octa-3,7-diene, New Electron Acceptors. Bull. Chem. Soc. Jpn. 2003, 76, 1793-1799. [CrossRef]

91. Simon, H.; Palm, D. Isotope Effects in Organic Chemistry and Biochemistry. Angew. Chem. Int. Ed. 1966, 5, 920-933. [CrossRef]

92. Nicholson, J.C.; Crist, B. Hydrogen-deuterium exchange for labeling polyethylene. Macromolecules 1989, 22, 1704-1708. [CrossRef]

93. Deflection Temperature Testing of Plastics. Available online: http://www.matweb.com/reference/deflection-temperature.aspx (accessed on 2 September 2021).

94. Kashin, A.S.; Ananikov, V.P. A SEM study of nanosized metal films and metal nanoparticles obtained by magnetron sputtering. Russ. Chem. Bull. 2011, 60, 2602-2607. [CrossRef] 